\title{
A Mix of Dietary Fibres Changes Interorgan Nutrients Exchanges and Muscle-Adipose Energy Handling in Overfed Mini-Pigs
}

\author{
Ahmed Ben Mohamed ${ }^{1}$, Didier Rémond ${ }^{1}$, Andreu Gual-Grau ${ }^{1}{ }^{\circledR}$, Annick Bernalier-Donnadille ${ }^{2}$, \\ Frédéric Capel ${ }^{1}$ (D), Marie-Caroline Michalski ${ }^{3}$, Fabienne Laugerette ${ }^{3}$, Benoit Cohade ${ }^{1}$, Noureddine Hafnaoui ${ }^{1}$, \\ Daniel Béchet ${ }^{1} \mathbb{D}$, Cécile Coudy-Gandilhon ${ }^{1}$ (D), Marine Gueugneau ${ }^{1} \mathbb{D}$, Jerome Salles ${ }^{1}$, Carole Migné ${ }^{4}$, \\ Dominique Dardevet $^{1}$, Jérémie David ${ }^{1}$, Sergio Polakof ${ }^{1}$ (D) and Isabelle Savary-Auzeloux ${ }^{1, *}$
}

Citation: Mohamed, A.B.; Rémond, D.; Gual-Grau, A.; Bernalier-Donnadille,

A.; Capel, F.; Michalski, M.-C.;

Laugerette, F.; Cohade, B.; Hafnaoui,

N.; Béchet, D.; et al. A Mix of Dietary

Fibres Changes Interorgan Nutrients

Exchanges and Muscle-Adipose

Energy Handling in Overfed

Mini-Pigs. Nutrients 2021, 13, 4202.

https://doi.org/10.3390/nu13124202

Academic Editor: David CameronSmith

Received: 25 October 2021

Accepted: 18 November 2021

Published: 23 November 2021

Publisher's Note: MDPI stays neutral with regard to jurisdictional claims in published maps and institutional affiliations.

Copyright: (C) 2021 by the authors Licensee MDPI, Basel, Switzerland This article is an open access article distributed under the terms and conditions of the Creative Commons Attribution (CC BY) license (https:// creativecommons.org/licenses/by/ $4.0 /)$
1 Unité de Nutrition Humaine (UNH), Unité Mixte de Recherches 1019, Université Clermont Auvergne, Institut National de Recherche pour l'Agriculture, l'Alimentation et l'Environnement (INRAE), 63000 Clermont-Ferrand, France; mohamed.ahmed.ben34@gmail.com (A.B.M.); didier.remond@inrae.fr (D.R.); andreu.gual-grau@inrae.fr (A.G.-G.); frederic.capel@inrae.fr (F.C.); benoit.cohade@inrae.fr (B.C.); noureddine.hafnaoui@inrae.fr (N.H.); daniel.bechet@inrae.fr (D.B.); cecile.coudy-gandilhon@inrae.fr (C.C.-G.); Marine.Gueugneau@inrae.fr (M.G.); jerome.salles@inrae.fr (J.S.); dominique.dardevet@inrae.fr (D.D.); jeremie.david@inrae.fr (J.D.); sergio.polakof@inrae.fr (S.P.)

2 Unité de Microbiologie Environnement Digestif et Santé, Unité Mixte de Recherches 0454, Université Clermont Auvergne, Institut National de Recherche pour l'Agriculture, l'Alimentation et l'Environnement (INRAE), 63000 Clermont-Ferrand, France; annick.bernalier@inrae.fr

3 CarMeN Laboratory, Unité Mixte de Recherches 1397, INRAE/Institut National de la Santé et de la Recherche Médicale (Inserm), Université Claude Bernard Lyon 1, Institut National de Recherche pour l'Agriculture, l'Alimentation et l'Environnement (INRAE), 69310 Pierre-Bénite, France; Marie-Caroline.Michalski@inrae.fr (M.-C.M.); fabienne.laugerette@univ-lyon1.fr (F.L.)

4 MetaboHUB Clermont, Plateforme d'Exploration du Métabolisme, Unité de Nutrition Humaine (UNH), Institut National de Recherche pour l'Agriculture, l'Alimentation et l'Environnement (INRAE), Université Clermont Auvergne, 63000 Clermont-Ferrand, France; carole.migne@inrae.fr

* Correspondence: isabelle.savary-auzeloux@inrae.fr

Abstract: This study evaluates the capacity of a bread enriched with fermentable dietary fibres to modulate the metabolism and nutrients handling between tissues, gut and peripheral, in a context of overfeeding. Net fluxes of glucose, lactate, urea, short chain fatty acids (SCFA), and amino acids were recorded in control and overfed female mini-pigs supplemented or not with fibre-enriched bread. SCFA in fecal water and gene expressions, but not protein levels or metabolic fluxes, were measured in muscle, adipose tissue, and intestine. Fibre supplementation increased the potential for fatty acid oxidation and mitochondrial activity in muscle ( $a c o x, u c p 2$, sdha and $c p t 1-m, p<0.05$ ) as well as main regulatory transcription factors of metabolic activity such as $p p a r \alpha, p g c-1 \alpha$ and $n r f 2$. All these features were associated with a reduced muscle fibre cross sectional area, resembling to controls (i.e., lean phenotype). SCFA may be direct inducers of these cross-talk alterations, as their feces content $(+52 \%, p=0.05)$ was increased in fibre-supplemented mini-pigs. The SCFA effects could be mediated at the gut level by an increased production of incretins (increased $g c g$ mRNA, $p<0.05$ ) and an up-regulation of SCFA receptors (increased gpr41 mRNA, $p<0.01$ ). Hence, consumption of supplemented bread with fermentable fibres can be an appropriate strategy to activate muscle energy catabolism and limit the establishment of an obese phenotype.

Keywords: overfeeding; dietary fibres; gene expression; SCFA; muscle metabolism; inter-organ metabolism; obesity

\section{Introduction}

In order to face the rapid increase of obesity and related diseases both in Europe and the US [1,2], the development of safe and efficient strategies capable of limiting weight 
gain and improving health status are in high demand. Among those, the increase in dietary fibre intake has been proven to be efficient in limiting weight gain, improving insulin sensitivity, maintaining metabolic homeostasis $[3,4]$ and correlated to a decreased risk of diabetes, cardiovascular diseases and even certain cancers $[5,6]$. However, less is known about these health benefits in a situation when the energy requirements are more than substantially exceeded. Yet, such situations occur frequently in obese or overfed populations when offered various naturally fibre-rich or fibre-enriched foods, two strategies regularly promoted by public health policies $[7,8]$.

The supplementation of dietary fibres in high fat/high sucrose or in over-fed rats has been proven to limit the deleterious diet-induced effects on body weight gain, insulin resistance, and microbiota composition, as well as gut and hepatic metabolism [9-11]. Such a similar effect has been shown in a pig model that is closer to humans in terms of nutritional habits, microbiota composition and digestive physiology/metabolism [12]. Our group recently showed that a mix of dietary fibres (resistant starch, pectin and inulin) was capable of limiting body weight gain and the hepatic accumulation of lipid droplets in overfed mini-pigs, probably via an alteration of PPAR-regulated lipids entry into the liver [13]. A significant part of the health-promoting effect of fibres should involve their fermentation products by gut microbiota such as short chain fatty acids (SCFAs) [14], particularly propionate and butyrate $[15,16]$. Indeed, SCFAs are known to present pleiotropic effects. At the splanchnic level, they impact on gut inflammation and gut incretin release [17,18], hepatic energy storage (as glycogen and lipid droplets) and utilization $[13,19,20]$. At the peripheral level (muscle and adipose tissues), few studies previously showed that (and how) SCFAs might modulate energy expenditure and storage [21,22].

Taken together, these data suggest that in a situation of over-nutrition or higher energy supply, the beneficial effects of dietary fibres (and/or their fermentation-derived products) at the whole body level are the result of tissues-specific metabolic adaptations and shifts in energy use vs. storage, with notably a direct impact on the splanchnic tissues, namely gut/microbiota and liver [13,23]. Meanwhile, peripheral tissues such as muscle and adipose tissues also adapt their metabolism after fibre supplementation and respond to signals which remain poorly explored and may involve directly or indirectly SCFAs $[21,24,25]$. Additionally, one cannot exclude digestive interactions between ingested fibres and lipids, known to reduce lipid absorption and play on lipids' endogenous secretions that could also explain part of the beneficial effects $[26,27]$.

In this context, the aim of the present study is dual. Firstly, explore how dietary fibre supplementation impacts on energy distribution between the splanchnic area and peripheral tissues in a situation of over-nutrition. Secondly, explore which metabolic pathways are regulated by fibre supplementation in the peripheral tissues (muscle and adipose). For these purposes, the nutrients net fluxes throughout the splanchnic tissues (gut and liver) and the gene expressions of major metabolic pathways involved in the utilization and storage of nutrients in the gut, muscle and adipose tissues were jointly investigated in overfed mini pigs. This work on dietary fibre supplementation in a context of over-nutrition is based on several previous studies we implemented on the same overfed Yucatan minipigs, whose metabolic response to diet has already been extensively unraveled [13,28-30] and has shown that the majority of phenotypes described are equivalent to what we can observe in humans.

\section{Materials and Methods}

\subsection{Animals and Experimental Procedure}

The study involved 20 female adult Yucatan mini-pigs with an average body weight of $34.8 \pm 1.5 \mathrm{~kg}$ at the beginning of the experiment. The animals were housed individually in pens $(1 \times 1.5 \mathrm{~m})$ in a ventilated room with controlled temperature $\left(21^{\circ} \mathrm{C}\right)$ and regular light cycle (L12:D12). Just before starting the experiment, the 20 animals were fed with $600 \mathrm{~g} /$ day of a standard diet (control diet (C)) $(2230 \mathrm{kcal} / \mathrm{kg})$ containing $69.2 \% \mathrm{starch}$, $17 \%$ protein, $3.3 \%$ fat, $5.5 \%$ cellulose, $5 \%$ ashes (Porcyprima; Sanders Centre Auvergne, 
Aigueperse, France) and had free access to tap water. This level of intake corresponds to the energy requirement for these pigs and corresponds to an overall supply of energy of $1300-1400 \mathrm{kcal} /$ day.

After this adaptation period, the animals were divided into 3 groups. Six pigs were used as control animals (group C). The remaining 14 mini-pigs were then surgically fitted with a catheter in the abdominal aorta, portal and hepatic veins. After 3 weeks of postsurgical recovery, 7 mini-pigs received an obesogenic diet (group O) for 56 days consisting of the standard diet $(800 \mathrm{~g})$ enriched with fat $(10 \%$ palm oil $w / w)$ and sugar $(10 \%$ sucrose $w / w)(2570 \mathrm{kcal} / \mathrm{kg})$ and $250 \mathrm{~g}$ of regular bread $(2044 \mathrm{kcal} / \mathrm{kg})$. The energy intake of these animals is $2640 \mathrm{kcal} / \mathrm{d}$. The last 7 mini-pigs received the same $800 \mathrm{~g}$ of the obesogenic diet, but regular bread was replaced by experimental bread $(1678 \mathrm{kcal} / \mathrm{kg})$ in which $23 \%$ of the flour was substituted with a mix of dietary fibres (group $\mathrm{O}+\mathrm{F}$ ) as previously described [31]. The fibre mix consisted of $20 \%$ inulin, $20 \%$ pectin and $60 \%$ resistant starch (Cargill, Minnetonka, Minnesota USA). The energy intake of the $\mathrm{O}+\mathrm{F}$ fed animals is $2621 \mathrm{kcal} / \mathrm{d}$. Food intake was recorded daily, and the animals' body weight was measured weekly as previously published [13].

After an overnight fast, blood from the portal vein, hepatic vein and abdominal aorta was sampled through the catheters on heparinized or EDTA tubes before the 1st day of overfeeding (D1) (i.e., samples obtained at D1 correspond to animals adapted to the standard diet (such as group C)), and after 14 days (D14) and 56 days (D56) of adaptation to each experimental diet $(\mathrm{O}$ or $\mathrm{O}+\mathrm{F})$. These time points have been chosen because they have been considered as key steps in the evolution of the phenotype of the Yucatan mini-pigs when overfed with a similar diet in a previous work [28], D14 corresponding to the early adaptation step associated with the diet change and D56 a longer adaptation equilibrium to the obesogenic diet. Fresh feces were also sampled at the same time points and stored at $-80{ }^{\circ} \mathrm{C}$ for further analysis. The experimental design has been previously published in detail [13]. Blood was centrifuged at $4500 \times g$ for $10 \mathrm{~min}$, plasma rapidly collected and stored at $-80{ }^{\circ} \mathrm{C}$ until further analyses. At D56 the mini-pigs of the groups $\mathrm{C}, \mathrm{O}$ and $\mathrm{O}+\mathrm{F}$ were euthanized after an overnight fast by intravenous administration of Dolethal ${ }^{\circledR}$ (pentobarbitone sodium $200 \mathrm{mg} / \mathrm{L}$, Vetoquinol ${ }^{\circledR}$, Lure, France). Samples of tissues (sub cutaneous adipose tissue, muscle (Longissimus dorsi)) were rapidly excised and freeze clamped. A sample of muscle tissue was fixed in ice isopentane and stored at $-80{ }^{\circ} \mathrm{C}$.

All procedures were in accordance with the guidelines formulated by the European Community for the use of experimental animals (L358-86/609/EEC, Council Directive, 1986) and the accreditation number for the present study is C63 34514.

For the measurement of plasma flow at D14 and D60, 1 hour before the blood samplings, a solution of $0.185 \mathrm{M}$ of sodium p-aminohippurate (PAH) (pH 7.4) was injected firstly as a flooding dose ( $5 \mathrm{~mL}$ of the PAH solution), then infused in the mesenteric vein at a rate of $12 \mathrm{~mL} / \mathrm{h}$. The plasma flows in each vessel were calculated according to the Fick principle [32]. It has to be noted that plasma flows and net nutrient fluxes data were shown at D14 and D56 because the fasted state studied represented an adaptation to a diet whose amount and composition at D1 (adaptation diet) was too different from the other 2 days of sampling (obesogenic diet \pm dietary fibres).

\subsection{Analytical Procedures}

Glucose, lactate, urea and triacylglycerol (TG) concentrations were enzymatically measured using commercial kits on a clinical chemistry analyser (ABX Pentra 400, Horiba Medical, Montpellier, France). Plasma lipoprotein binding protein and interleukin 6 (IL-6) levels were assayed using commercial ELISA kits (Cliniscience, Nanterre, France and Sigma Aldrich, St. Louis, MI, USA, respectively). Beta-hydroxybutyrate (BHB) and ammonia were enzymatically measured using a commercial kit (Sigma Aldrich, St. Louis, MI, USA).

For amino acids (AA) measurement, detailed procedures are described elsewhere [33]. Shortly, plasma samples were deproteinised with sulphosalicylic acid after adding norleucine $(50 \mu \mathrm{L}, 1.25 \mathrm{mmol} / \mathrm{L})$ as an internal standard. The supernatant was diluted (2/3) 
with a lithium injection buffer (Bioritech, Guyancourt, France) containing glucosaminic acid as an injection standard and AA concentrations were determined with an AA analyzer (Hitachi L8900, Sciencetec, Villebon/Yvette, France) by ion exchange chromatography (with post-column derivatisation with ninhydrine. Essential amino acids (EAA) included histidine, isoleucine, leucine, lysine, methionine, phenylalanine, threonine, tryptophane and valine; non-essential amino acids (NEAA) included alanine, glutamate, glutamine, glycine, serine, tyrosine, cystine, citrulline, ornithine, arginine, proline, asparagine, aspartate and taurine and branched-chain amino acids (BCAA) included isoleucine, leucine and valine. Total amino acids (TAA) were the sum of IAA and NIAA.

PAH concentration in plasma was measured according to [34], $250 \mu \mathrm{L}$ of plasma samples were deproteinized with sulphosalicylic acid, thoroughly mixed and centrifuged at $10,000 \times g, 4{ }^{\circ} \mathrm{C}$, for $15 \mathrm{~min} .80 \mu \mathrm{L}$ of the supernatant was deacetylated by adding $20 \mu \mathrm{L}$ of $5 \mathrm{M} \mathrm{HCL}$ followed by an incubation at $90^{\circ} \mathrm{C}$ for $1 \mathrm{~h}$ [35]. Sodium nitrite $(625 \mathrm{mg} / \mathrm{L})$ was then added manually. The samples were then inserted into the automotive ABX Pentra 400 (Horiba Medical, France), which added successively ammonium sulfamate $(0.64 \mathrm{~g} / \mathrm{L})$ and $\mathrm{N}$-(1-Naphtyl) ethylenediamine dihydrochloride $(1 \mathrm{mg} / \mathrm{mL})$. Concentrations were then determined by comparison with PAH standard and read out at $600 \mathrm{~nm}$.

SCFAs in plasma were measured using 1-(tert-butyldimethylsilyl) imidazole (MTBSTFA) derivatization and analysis by gas chromatography (GC) according to Pouteau et al., 2001 [36]. Shortly, to $500 \mu \mathrm{L}$ of plasma was added $50 \mu \mathrm{L}$ of a mixture of ${ }^{13} \mathrm{C}$ labelled $1{ }^{13} \mathrm{C}$ acetate $(4 \mathrm{mM}), 1-{ }^{13} \mathrm{C}$-propionate $(1.5 \mathrm{mM}), 1{ }^{13} \mathrm{C}$-butyrate $(0.6 \mathrm{mM})$ (Cortecnec, Voisins Le Bretonneux, France) and $10 \mu \mathrm{L}$ of $37 \%(v / v)$ HCL solution. $2 \mathrm{~mL}$ of diethyl ether was added to plasma and the mixture was centrifuged (10 min, $2000 \mathrm{rpm}$ ). $50 \mu \mathrm{L}$ of MTBSTFA (Tokyo Chemical Industry, Tokyo, Japan) was added to the supernatant for SCFA derivatization. The mixture was injected in GC-MS system 7890A (Agilent Technologies, Santa Clara, CA, USA) using the splitless mode equipped with a quadrupole detector (5975C) and autoinjector (7683). The ionisation mode was operated in electron impact (electron energy $70 \mathrm{eV}$ ). The GC system was fitted with a nonpolar capillary column DB-5 MS (J\&W Scientific, Folsom, CA, $30 \mathrm{~m} \times 0.25 \mathrm{~mm}$ i.d $\times 0.25 \mu \mathrm{m}$ film thickness) for chromatographic separation. Quantification of the SCFA was performed using the Selected Ion Monitoring acquisition Mode by measurement of the $\mathrm{m} / \mathrm{z}$ ratios of the specific ${ }^{13} \mathrm{C}$ and ${ }^{12} \mathrm{C}$ ions of each quantified SCFA and comparison to a standard curve: $118 / 117\left(1-{ }^{13} \mathrm{C}\right.$-acetate $/{ }^{12} \mathrm{C}$ acetate), 132/131 (1- ${ }^{13} \mathrm{C}$-propionate $/{ }^{12} \mathrm{C}$ propionate), $146 / 145$ (1- ${ }^{13} \mathrm{C}$-butyrate $/{ }^{12} \mathrm{C}$ butyrate). SCFA production in feces was quantified by 1D 1H NMR in water-extracted fecal samples (560 $\mu \mathrm{L})$ with TSPD4 as an internal standard. Fecal water was obtained as previously described [37].

Measurements on muscle fibres' cross-sectional area (CSA) were performed on muscle $10 \mu \mathrm{m}$ thick cross-sections obtained at $-20^{\circ} \mathrm{C}$ using a cryostat (HM500M Microm International, Fisher Scientific, Illkirch, France) and labeled with anti-laminin- $\alpha 1$ (L9393-Sigma). Observations and image acquisitions were captured with a high-resolution, cooled digital DP-72 camera coupled to a BX-51 microscope (Olympus) and Cell-D software (Olympus Soft Imaging Solutions, Münster, Germany). The images analysis was performed using the Visilog 6.9 software (Noesis, Crolles, France).

\subsection{RNA Extraction and Quantification}

Total RNA from subcutaneous adipose tissue (300 mg), Longissimus dorsi muscle $(150 \mathrm{mg})$, proximal caecum $(100 \mathrm{mg})$ and jejunum $(50 \mathrm{mg})$ were isolated by using a PureLink RNA Mini Kit (Invitrogen, Thermo Fisher Scientific, Waltham, MA, USA) according to manufacturer's protocol. Before sample processing with column RNAse-free, tissues were homogenized in $1 \mathrm{~mL}$ (muscle, caecum, jejunum) or $2 \mathrm{~mL}$ (subcutaneous adipose) of TRIzol Reagent (Ambion, Life Technologies, Carlsbad, CA, USA), then were centrifuged $\left(10,000 \times g\right.$ for 5 or $10 \mathrm{~min}$ at $\left.4{ }^{\circ} \mathrm{C}\right)$. The upper phase was collected and added with $200 \mu \mathrm{L}$ (muscle, caecum, jejunum) or $250 \mu \mathrm{L}$ (subcutaneous adipose) of chloroform. After shaking vigorously for $15 \mathrm{~s}$, the tubes were centrifuged $\left(12,000 \times \mathrm{g}\right.$ for $5 \mathrm{~min}$ at $\left.4{ }^{\circ} \mathrm{C}\right)$. The upper phase (muscle, caecum, jejunum) was carefully transferred to an RNAse-free 
column. The aqueous phase of the subcutaneous adipose tissue was washed again with $400 \mu \mathrm{L}$ of chloroform before being centrifuged and transferred to an RNAse-free column (invitrogene). RNA samples purity was verified using NanoDrop spectrophotometer (ND1000, NanoDrop Technologies Inc., Wilmington, DE, USA) and RNA (1 $\mu \mathrm{g})$ integrity was verified on $1 \%$ agarose ethidium-bromide-stained gel. cDNA was obtained from $1 \mu \mathrm{g}$ of RNA using the high-capacity cDNA reverse transcription kit (AB Applied Biosystems, Foster City, CA, USA), containing a mix of random primers and oligo(dT), according to the manufacturer's instructions.

\subsection{Quantitative Real-Time PCR (RT-qPCR) Methods and Data Analysis}

cDNA was diluted 1:20 in RNAse-free water. Pre-amplification was performed using PowerUp SYBR Green Master Mix (AB Applied Biosystems, Life Technologies, Woolston Warrington, UK). Real-time quantitative PCR was carried out on a Bio-Rad CFX-96 detection system with quantitative qPCR SYBR Green reagents. Primers were designed to span intron/exon boundaries (preventing the amplification of contaminating genomic DNA) using Primer3 software (Whitehead Institute for Biomedical Research/MIT Center, Cambridge, MA, USA), while gene sequences were obtained from public databases (PubMed, Ensembl) (Table 1). PowerUp SYBR Green Master Mix $(7.5 \mu \mathrm{L})$ was mixed with $0.3 \mu \mathrm{L}$ of forward $(10 \mu \mathrm{M})$ and reverse $(10 \mu \mathrm{M})$ primer mix and $2 \mu \mathrm{L}$ of diluted cDNA, and incubated at $95^{\circ} \mathrm{C}$ for $10 \mathrm{~min}$. PCR conditions were standardized to 40 cycles of: $95^{\circ} \mathrm{C}$ for $15 \mathrm{~s}, 59^{\circ} \mathrm{C}$ for $30 \mathrm{~s}$ and $65^{\circ} \mathrm{C}$ for $5 \mathrm{~s}$. Relative quantification of the target genes was conducted using eef1 $\alpha$ housekeeping gene (caecum, jejunum). Relative quantification was made using the comparative $\Delta \Delta \mathrm{Ct}$ method for muscle (using $r p s 9, t b p$, gapdh and $h r p 1$ as reporter genes) and subcutaneous adipose (using actin, eef1 $\alpha, r p s 9$, tbp, gapdh and $h r p 1$ as reporter genes).

\subsection{Calculations}

Net nutrient fluxes through the gut (viscera drained by the portal vein), the liver and total splanchnic tissues (gut + liver) were calculated based on princeps studies from Katz et al., 1969 [32]. Shortly, the net nutrient fluxes were calculated as differences between the afferent flux and the efferent flux. Consequently, a positive net flux indicates a net release whereas a negative net flux indicates a net uptake. Metabolites (MET) net gut release (or net portal appearance) was calculated as follows: $\left([\mathrm{MET}]_{\mathrm{PV}}-[\mathrm{MET}]_{\mathrm{A}}\right) \times \mathrm{PF}_{\mathrm{PV}}$ where $\mathrm{PF}_{\mathrm{PV}}$ is the portal plasma flow, $[\mathrm{MET}]_{\mathrm{PV}}$ and $[\mathrm{MET}]_{\mathrm{A}}$ the metabolite concentrations in the portal vein and the artery, respectively. The net hepatic flux of metabolites was calculated as follows: $\left([\mathrm{MET}]_{\mathrm{HV}} \times \mathrm{PF}_{\mathrm{HV}}-\left([\mathrm{MET}]_{\mathrm{PV}} \times \mathrm{PF}_{\mathrm{PV}}+[\mathrm{MET}]_{\mathrm{A}} \times \mathrm{PF}_{\mathrm{AH}}\right)\right.$ where $[\mathrm{MET}]_{\mathrm{HV}, \mathrm{PV}}$ and ${ }_{\mathrm{A}}$ is the metabolite concentrations in the hepatic vein, portal vein and artery, respectively, and $\mathrm{PF}_{\mathrm{HV}, \mathrm{PV}}$ and ${ }_{\mathrm{A}}$ are the plasma flows in the hepatic vein, portal vein and artery, respectively. Lastly, the net flux of metabolites across overall splanchnic tissues was calculated as follows: $\left([\mathrm{MET}]_{\mathrm{HV}}-[\mathrm{MET}]_{\mathrm{A}}\right) \times \mathrm{PF}_{\mathrm{HV}}$ where $\mathrm{PF}_{\mathrm{HV}}$ is the plasma flow in the hepatic vein and $[\mathrm{MET}]_{\mathrm{HV}}$ and ${ }_{\mathrm{A}}$ the metabolite concentrations in the hepatic vein and artery.

\subsection{Statistics}

All data are expressed as means \pm SEM. Comparisons of data between D1, D14 and D56 in the fasted state for plasma metabolites concentrations and D14 and D56 for net nutrient fluxes were performed using a two way (time and diet effects) repeated measures ANOVA (SigmaPlot 12, Systat software, San Jose, CA, USA) followed by a post hoc analysis using the Tukey test.

Comparisons between diets at D56 (data obtained in tissues) in the fasted state were obtained using a one-way ANOVA (SigmaPlot 12, Systat software, San Jose, CA, USA) followed by a post hoc analysis using the Tukey test. Comparisons between diets for the muscle fibre cross-sectional area was determined by Student's $t$-test calculated for each fibre-size range. Differences were considered significant if $p<0.05$ and as a tendency (t) for $0.05<p<0.1$. 
Table 1. Primer sequences used for qrt-pcr.

\begin{tabular}{|c|c|c|}
\hline Gene Symbol & Primer Sequence (Forward) & Primer Sequence (Reverse) \\
\hline$A \operatorname{cox}$ & GACCTGAGCGGCCTACCTGA & CATCAGGAACCTGGCCGTCT \\
\hline$\beta-A c t$ & GCGGCATCCACGAAACTACC & CTCTGGAGGCGCGATGATCT \\
\hline Angptl4 & CTCTGGTGGTTGGTGGTTTG & GCTACTGTGGGCTGGATCA \\
\hline Cpt1 & GACGAGGACCCCTGATGGTG & CGTGGATCCCAGGAGAATCG \\
\hline$C p t-m$ & CTGCAGGGGGAAGAGTGGAG & TTGAACGCGATGAGGGTGAA \\
\hline Cpt2 & TACGAGTCCTGTAGCACTGC & TGGTTGTGGTACTCGGAACA \\
\hline Eef1a & ACCTGTGCTGGATTGCCACA & AACAGCAAATCGGCCCAGAG \\
\hline Fasn & CGGTTCCAAGGAGCAAGGTG & GCATTCACGATGCCGTTCAG \\
\hline Gapdh & ACGGTCCATGCCATCACTG & CCAGTGAGCTTCCCGTTGA \\
\hline Gcg & CCCAGGATTTTGTGCAGTGG & GCAATGAATTCCTTGGCAGC \\
\hline Gpr41 & CTCCGTGTACCTCTTGACGT & AGACGGTGGTGAAGAAGAGG \\
\hline Gpr43 & GAGTGATTGCTGCTCTGGTG & TGGGGATGAAGAAGAGGACG \\
\hline Glut4 & GCCCGCGAGAAAGAGTCTGA & GCCGTCTCGAAGATGCTGGT \\
\hline Hk1 & AGCTAAGAGTCCTGGCCCCC & CGCCATTAGGTGGCTTCTGC \\
\hline Hprt1 & TATGGACAGGACTGAACGGC & TGGTCATTACAGTAGCTCTTCAG \\
\hline Hsl & CGTCTCTAGCAAACATGGCA & TCACTGTCCTGTCCTTCACG \\
\hline Il-6 & TGGGTTCAATCAGGAGACCT & GTGGTGGCTTTGTCTGGATT \\
\hline Mct1 & TGGCTGTCATGTATGGTGGA & AAGCCCAAGACCTCCAATGA \\
\hline Nrf2 & ATTCCCAGGTTTCTTCGGCT & TGGAACCGTGCTAGTCTCAG \\
\hline Pepck-m & CTGGAAACCCGGTGACAAGG & GGGGGACTCCTTTGGGTCTG \\
\hline$P G C-1 \alpha$ & AGGCAGAAGGCAATTGAAGA & TTTCAAGAGCAGCAAAAGCA \\
\hline Ppara & CAGCAATAACCCGCCTTTCG & ACTTGGCGAACTCCGTGAGC \\
\hline Pparg & TGTGAAGGATGCAAGGGTTTC & CAACAGCTTCTCСTTCTCAGC \\
\hline Rps9 & TTGAAGGGAATGCTCTGCTG & GGACAATGAAAGGACGGGATG \\
\hline Srebp-1c & AGGCAGCACCTTTGCAGACC & GCGGTAGCGTTTCTCGATGG \\
\hline Sdha & CCTCCGTGGTAGAGCTAGAG & TACCGCAGAGACCTTTCCGTA \\
\hline Slc27a4 & TGCAGTACATTGGCGAGCT & ACACTGGCCGTCAAAGTTG \\
\hline Tbp & TTTTGGAGGAGCAGCAAAGG & GTGGAAGAGCTGTGGAGTCT \\
\hline Tnfa & TGTAGCCAATGTCAAAGCCG & ATGGCAGAGAGGAGGTTGAC \\
\hline Ucp2 & TCGACGCCTACAAGACCATC & GCAGGGAAGGTCATCTGTCA \\
\hline
\end{tabular}

Acox, Acyl-coA oxidase 1 and 2; $\beta$-Act, $\beta$-actin; Angptl4, angiopoietin like 4, Cpt1, Carnitine o-palmitoyl transferase 1; Cpt1-m, Carnitine o-palmitoyl transferase 1 muscular; Cpt2, Carnitine o-palmitoyl transferase 2; Eef1a, Elongation factor 1-alpha; Fas, Fatty acid synthase; Gapdh, Glyceraldehyde-3-phosphate dehydrogenase; Gcg, Glucagon precursor; Gpr41, G protein-coupled receptor 41; Gpr43, G protein-coupled receptor 43; Glut4, Glucose transporter type 4; Hk1, Hexokinase-1; Hprt1, Hypoxanthine phosphoribosyltransferase 1; Hsl, Hormone-sensitive lipase; Il-6, Interleukin-6; Mct1, Monocarboxylate transporter 1; Nrf2, Nuclear factor erythroid 2-related factor 2; Pgc-1 $\alpha$, Peroxisome proliferator-activated receptor-gamma coactivator- $1 \alpha$; Pepck-m, Phosphoenolpyruvate carboxykinase muscular; Ppar $\alpha$, Peroxisome proliferator-activated receptor alpha; Pparg, Peroxisome proliferator-activated receptor gamma; Rps9, Ribosomal protein S9; Srebp-1c, Sterol regulatory element-binding protein; Sdha, Succinate dehydrogenase complex flavoprotein subunit A; Slc27a4, Solute carrier family 27 member 4; Tbp, TATA-box binding protein; Tnf $\alpha$, Tumor necrosis factor; Ucp2, Uncoupling protein 2.

\section{Results}

The impact of overfeeding associated or not with dietary fibre supplementation on our animals' metabolic phenotype can be found in a paper published previously [13]. Indeed, we reported in our previous work a significant body weight gain, alterations of metabolic parameters such as fasted plasma insulin $(+88 \%)$, HOMA-IR $(+102 \%)$, cholesterol $(+45 \%)$ and lactate $(+63 \%)$ at D56 compared to D1 and increased lipids accumulation in the liver following overfeeding relative to control animals fed at a maintenance level. Dietary fibre supplementation limited body weight gain and hepatic lipids infiltration. In the present article, the impact of the dietary fibre supplementation is targeted on two peripheral tissues (muscle, adipose tissue) and the gut. Our aim is to highlight the metabolic adaptation of the peripheral tissues (and potential causes) to overfeeding associated or not with fibres, in the fasted state. For the latter purpose, we analyzed (1) the adaptation of various metabolic pathways within muscle and adipose in a situation of nutrients overflow (in presence or not of dietary fibres in the diet), and (2) the net nutrients fluxes at the gut level as this organ is an important user/emitter of various nutrients that can modulate (or be the consequence of) the adaptations of metabolic pathways in the peripheral tissues. The study of the 
splanchnic area can highlight some explanatory mechanisms of metabolic adaptations observed at the peripheral level.

\subsection{Impact of Dietary Fibre Supplementation on Muscle (Longissimus dorsi) Phenotype and Gene Expression}

Overnutrition induced a shift in the Longissimus dorsi fibre size, with an increased number of larger muscle fibres in the $\mathrm{O}$ group relatively to both $\mathrm{O}+\mathrm{F}$ and $\mathrm{C}$, especially for muscle fibres cross-sectional area (CSA) ranging from $6300-7000$ to $9100-9800 \mu^{2}$ $(p<0.05)$ (Figure 1A). Remarkably, muscle fibre size distribution was similar between C and $\mathrm{O}+\mathrm{F}$ animals. Glycogen content in the muscle at D56 was significantly lower in the $\mathrm{O}$ group compared to $\mathrm{C}(-48 \%, p<0.05)$, while fibre supplementation attenuated the dietary impact on glycogen storages $(\mathrm{O}+\mathrm{F}$ not different from $\mathrm{O}$ and $\mathrm{C})$ (Figure 1C). Fasting triglycerides content in muscle from the three groups was not significantly different at D56 (Figure 1B).

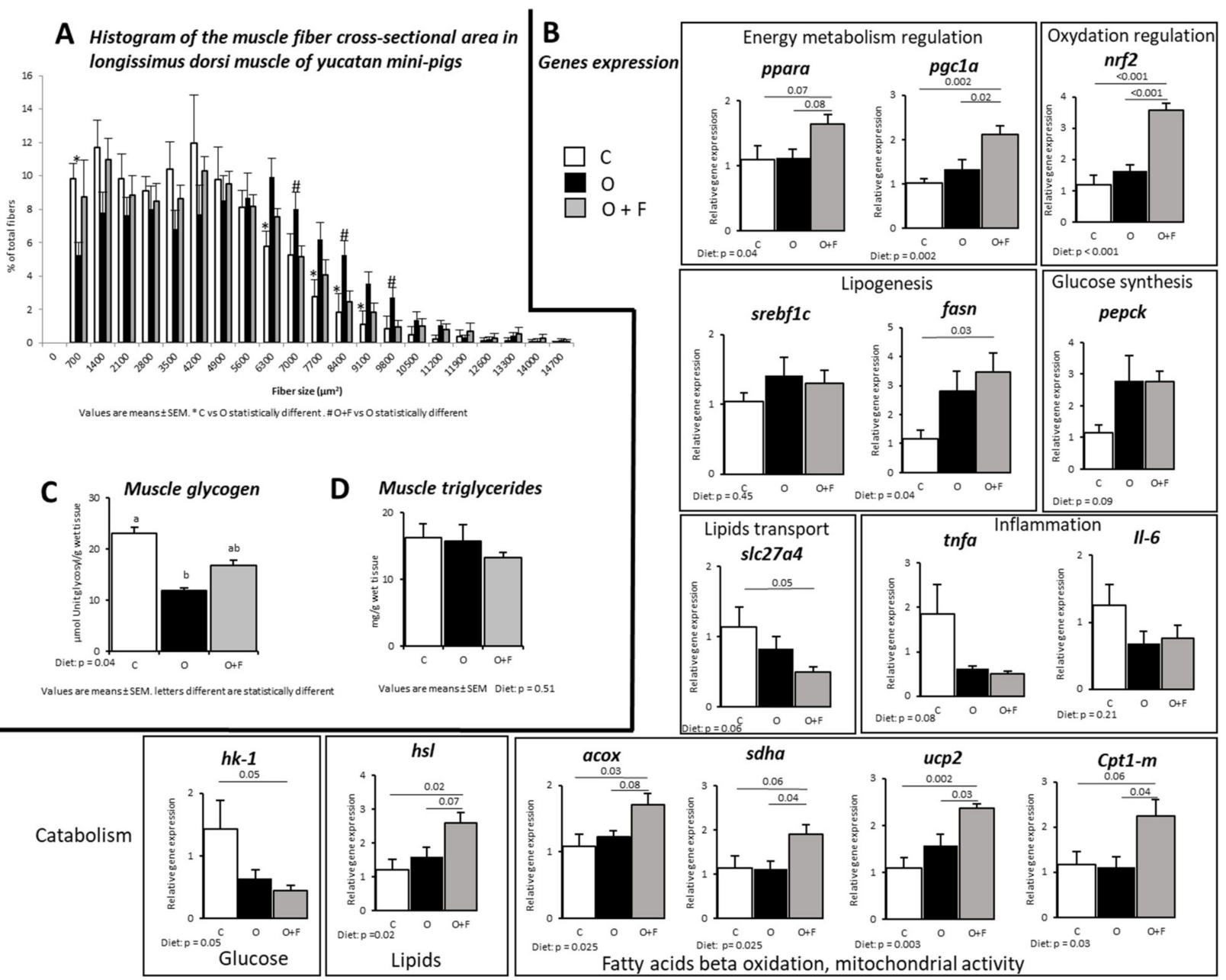

Figure 1. Muscle (longissimus dorsi) metabolic activity in mini-pigs fed a control (C) diet, following 56 days of overnutrition (O) or 56 days of overnutrition and supplementation with a mix of dietary fibres $(\mathrm{O}+\mathrm{F})$. (A) Histogram of the muscle fibres cross-sectional area. (B) Gene expression in the fasted state. (C) Fasting glycogen content in muscle at D56. (D) Fasting triglycerides content in muscle at D56. Data are expressed as the mean \pm S.E.M. Significant differences are considered when $p<0.05$. acox, Acyl-CoA oxidase; cpt1-m, carnitine O-palmitoyltransferase 1 muscular; fasn, fatty acid synthase; $h k$-1, hexokinase-1; hsl, hormone-sensitive lipase; Il-6, interleukine-6; nrf2, nuclear factor erythroid 2-related factor 2; pepck, phosphoenolpyruvate carboxykinase; PGC-1 $\alpha$, peroxisome proliferator-activated receptor gamma coactivator 1-alpha; ppara, peroxisome proliferator-activated receptor alpha; sdha, succinate dehydrogenase complex flavoprotein subunit A; slc27a4, solute carrier family 27 member 4; srebp 1c, sterol regulatory element-binding protein; $t n f \alpha$, tumor necrosis factor alpha; ucp2, uncoupling protein 2. 
Many gene expressions measured at the fasted state concurred to show that fibre supplementation limited muscle lipid entry/storage and facilitated lipid catabolism. Indeed, several genes involved in fatty acid oxidation and mitochondrial activity were overexpressed in the $\mathrm{O}+\mathrm{F}$ group relatively to both the $\mathrm{C}$ and $\mathrm{O}$ groups $(+41 \%,+72 \%,+51 \%$, $+102 \%$ in $\mathrm{O}+\mathrm{F}$ vs. O for acox $(p=0.08)$, sdha $(p=0.04), u c p 2(p=0.03)$ and $c p t 1-m(p=0.04)$, respectively), suggesting an increased activity of oxidative and mitochondrial activity in the fibre-supplemented pigs (Figure 1B). For these four genes, the $\mathrm{C}$ and $\mathrm{O}$ groups were not different.The $h s l$ gene regulating the degradation of triglycerides into free fatty acids was also more expressed in the fibre-supplemented overfed group than in the control and non-supplemented overfed animals $(+116 \%$ in $\mathrm{O}+\mathrm{F}$ vs. C, $p=0.02 ;+63 \%$ in $\mathrm{O}+\mathrm{F}$ vs $\mathrm{O}, p=0.07)$. Moreover, the expression of Slc27a4, a gene related to lipids entry into the myocytes, was significantly decreased in the fibre-supplemented pigs $(-57 \%$ in $\mathrm{O}+\mathrm{F}$ vs. $\mathrm{C}, p=0.05$ ), whereas the $\mathrm{O}$ animals showed intermediate values (not significantly different from the $\mathrm{C}$ and $\mathrm{O}+\mathrm{F}$ groups).

In adaptation to overfeeding conditions, fibre supplementation did not alter the expression of enzymes involved in de novo lipogenesis ( $f a s n$ ) compared to the $\mathrm{O}$ group $(\mathrm{O}+\mathrm{F}$ vs. $\mathrm{O}, p=0.72)$, whereas it was significantly increased compared to $\mathrm{C}(+195 \%$ in $\mathrm{O}+\mathrm{F}$ vs. $\mathrm{C}, p=0.03)$. However, despite that fatty acids can be synthetized in the muscle, the global contribution of de novo lipogenesis to total myocytes' fatty acid flux can be considered as minor [38].

Hexokinase ( $h k 1)$, involved in glucose (or other hexoses) phosphorylation (i.e., first step of glycolysis), gene expression in muscle was significantly decreased in the $\mathrm{O}+\mathrm{F}$ group $(-69 \%$ in $\mathrm{O}+\mathrm{F}$ vs. C, $p=0.05)$ but not in the $\mathrm{O}$ group $(-54 \%$ in O vs. $\mathrm{C}, p=0.14)$. These genes are regulated by several proteins such as srebp $1 c$, whose expression levels were similar between the $\mathrm{C}, \mathrm{O}$ and $\mathrm{O}+\mathrm{F}$ groups. However, the expression levels of genes encoding for other proteins involved in the regulation of energy metabolism and homeostasis were uniquely increased in the fibre-supplemented pigs: ppar $\alpha$ and $p g c 1-\alpha(+50 \%$ and $+107 \%$ in $\mathrm{O}+\mathrm{F}$ vs. $\mathrm{C}, p=0.07$ and $p<0.01$, respectively; $+46 \%$ and $+58 \%$ in $\mathrm{O}+\mathrm{F}$ vs. $\mathrm{O}, p=0.08$ and $p=0.02$, respectively), whereas these gene expressions remained unaltered between the $C$ and $\mathrm{O}$ groups. In the same way, the transcription factor $n r f 2$, involved in the regulation of antioxidant response, was strongly increased by fibre supplementation $(+197 \%$ in $\mathrm{O}+\mathrm{F}$ vs. $\mathrm{C}, p<0.01 ;+182 \%$ in $\mathrm{O}+\mathrm{F}$ vs. $\mathrm{O}, p<0.01)$, whereas $\mathrm{C}$ and $\mathrm{O}$ were similar. Lastly, the expression of $\operatorname{tnf} \alpha$ and $I l-6$ was not altered after any dietary treatment.

\subsection{Impact of Dietary Fibre Supplementation on Subcutaneous Adipose Tissue, Caecum and Jejunum Genes Expression}

Contrary to muscle, some but not all genes measured involved in fatty acids beta oxidation and mitochondrial activity were increased by fibre supplementation in adipose tissues (Figure 2). This was the case for acox, whose expression tended to increase only in the $\mathrm{O}+\mathrm{F}$ group vs. $\mathrm{C}(p=0.07)$, with $\mathrm{O}$ intermediate (Figure 2). Moreover, the overfeeding induced a down-regulation of $c p t 1-l$ gene expression $(-50 \%$ in $\mathrm{O}$ vs. $\mathrm{C}, p=0.002)$, which was reverted by fibre supplementation with an increased cpt $1-l$ expression $(+64 \%$ in $\mathrm{O}+\mathrm{F}$ vs. $\mathrm{O}, p=0.05)$, thereby restoring an expression similar to C. For mitochondrial cpt2 and sdha gene expression, $\mathrm{O}$ and $\mathrm{O}+\mathrm{F}$ were similar but up-regulated relatively to $\mathrm{C}$ (Diet effect, $p=0.004$ and $p=0.02$ for $c p t 2$ and $s d h a$, respectively). Aside from oxidative activity, a stimulation of fatty acids synthesis potential, measured by fasn gene expression, was observed by overfeeding independently of dietary fibre supplementation (Diet effect, $p=0.001$ ), whereas triglycerides hydrolysis potential (measured by hsl gene expression) was not affected by dietary intervention.

These metabolic processes are under the regulatory control of several transcription factors such as ppar $\alpha$ and srebf1c, related to mitochondrial fatty acid $\beta$-oxidation and adipocyte lipogenesis, respectively. The gene expression of ppar $\alpha$ was increased by fibre supplementation relatively to both the control and overfed animals $(+94 \%$ in $\mathrm{O}+\mathrm{F}$ vs. $\mathrm{C}, p<0.05$; $+41 \%$ in $\mathrm{O}+\mathrm{F}$ vs. O, $p<0.05)$. However, srebf1c expression levels, dependent on $p p a r \alpha$ regulatory control, remained unaltered in this tissue (Diet effect, $p=0.16$ ). Finally, angptl4 
gene expression, involved in the regulation of glucose homeostasis, lipid metabolism and insulin sensitivity, was significantly down-regulated in the $\mathrm{O}+\mathrm{F}$ group compared to controls $(-50 \%$ in $\mathrm{O}+\mathrm{F}$ vs. C, $p=0.036)$, with $\mathrm{O}$ in-between.

\section{Adipose tissue}

Caecum
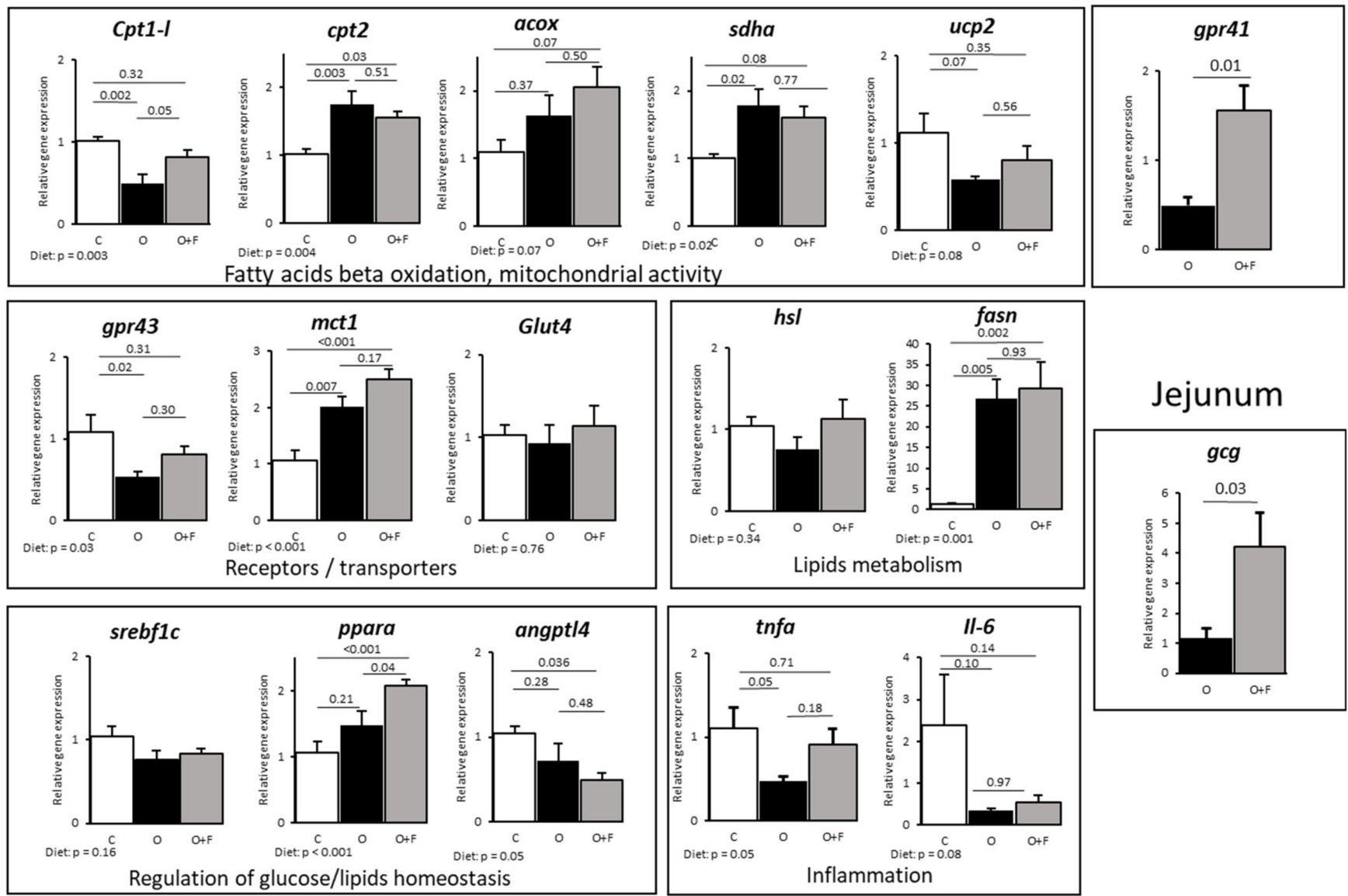

Jejunum

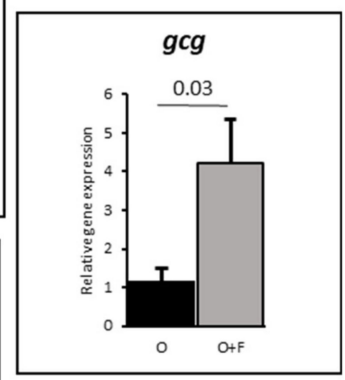

Figure 2. Adipose (subcutaneous) tissue, caecum and jejunum genes expression in mini-pigs fed a control (C) diet, following 56 days of overnutrition $(\mathrm{O})$ or 56 days of overnutrition and supplementation with a mix of dietary fibres $(\mathrm{O}+\mathrm{F})$. Data are expressed as the mean \pm S.E.M. Significant differences are considered when $p<0.05$. acox, acyl-CoA oxidase; angptl4, angiopoietin-like 4; cpt1 and 2, carnitine O-palmitoyltransferase 1 and 2; fasn, fatty acid synthase; gcg, glucagon precursor; glut4, glucose transporter type 4; gpr43 and 41, G-protein-coupled receptor 43 and 41; hsl, hormone-sensitive lipase; Il-6, interleukine-6; mct1, monocarboxylate transporter 1; ppar, peroxisome proliferator-activated receptor alpha; sdha, succinate dehydrogenase complex flavoprotein subunit A; srebf1c, sterol regulatory element-binding protein; $t n f \alpha$, tumor necrosis factor alpha; $u c p 2$, uncoupling protein 2.

Regarding sugar entry into adipose tissue, the glut4 glucose transporter was not modified by dietary intervention (Diet effect, $p=0.76$ ) whereas the lactate $m c t 1$ transporter expression was significantly increased in overfed animals regardless of fibre supplementation $(+89 \%$ in O vs. C, $p=0.007 ;+134 \%$ in $\mathrm{O}+\mathrm{F}$ vs. C, $p<0.001)$. Finally, gpr43 (G protein-coupled receptor 43, specific for SCFAs) expression levels were down-regulated by overfeeding $(-50 \%$ in $\mathrm{O}$ vs. C, $p=0.02)$, whereas fibre supplementation restored partially its expression, with no longer differences between the $\mathrm{O}+\mathrm{F}$ and $\mathrm{C}$ groups. Concerning inflammation, $t$ f $f \alpha$ expression was decreased after 2 months of overfeeding $(-58 \%$ in O vs. $C, p=0.05$ ) whereas the $\mathrm{O}+\mathrm{F}$ group was similar to control normally fed animals. Il-6 expression was not significantly modified. 
At the gut level, gene expression of SCFA receptor gpr41 in caecum, and pro glucagon, Glp1 and Glp2 encoding gene $(g c g)$ in jejunum were both up-regulated in the fibresupplemented group $(+214 \%$ and $+262 \%$ in $\mathrm{O}+\mathrm{F}$ vs. O for $\operatorname{gpr} 41(p=0.01)$ and $g c g$ $(p=0.03)$, respectively), as shown in Figure 2.

\subsection{Fasting Concentration of Circulating Metabolites}

Arterial concentrations of insulin, lactate, BHB, propionate, and selected AA (leucine, valine, isoleucine, phenylalanine, methionine, histidine, alanine, glutamate, glycine, serine, arginine, citrulline, cysteine, ornithine, asparagine, aspartate, taurine), as well as HOMA-IR, were significantly altered by overfeeding independently of fibre supplementation (Time effect, $p<0.5)$, but only alanine tended to be significantly different between the $\mathrm{O}$ and $\mathrm{O}+\mathrm{F}$ groups (Diet effect, $p=0.07$ ) (Table 2). Arterial values for part of these metabolites are already presented in a previous paper [13].

Many metabolites present at the hepatic vein level, thus representing those released by the splanchnic area and available for peripheral tissues, were significantly altered by overfeeding regardless of fibre supplementation, including lactate, BHB, acetate, total SCFAs and many AA including isoleucine, valine, phenylalanine, methionine, histidine, glutamate, glycine, arginine, citrulline, ornithine, asparagine and taurine (Time effect, $p<0.05$ ) (Table 2). Remarkably, dietary fibre supplementation tended to increase hepatic vein concentrations for acetate and total SCFAs (Diet effect, $p=0.06$ ), and glucose especially at D56 (Diet $\times$ Time, $p=0.07$ ) (Table 2). Moreover, the appearance of other metabolites over time, such as alanine (Diet effect, $p=0.06$, Diet $\times$ Time, $p=0.10$ ), glutamine (Diet $\times$ Time effect, $p=0.08$ ), and ornithine (Diet $\times$ Time effect, $p=0.07$ ) tended to be altered specifically by dietary fibre supplementation.

Table 2. Plasma biochemical parameters in mini-pigs in the fasted state before (D1) and after 14 (D14) and 56 days (D56) of adaptation to overfeeding and control bread supplementation $(\mathrm{O})$ or overfeeding and bread supplemented with fibre mixture $(\mathrm{O}+\mathrm{F})$ in the artery $(\mathrm{A})$ or hepatic vein $(\mathrm{HV})$.

\begin{tabular}{|c|c|c|c|c|c|c|c|c|c|c|c|c|}
\hline & & \multicolumn{4}{|c|}{$\mathbf{O}$} & \multicolumn{4}{|c|}{$\mathrm{O}+\mathrm{F}$} & \multicolumn{3}{|c|}{$p$ Value } \\
\hline & & D1 & D14 & D56 & SEM & D1 & D14 & D56 & SEM & Diet & Time & Diet $\times$ Time \\
\hline Insulin $(\mu \mathrm{g} / \mathrm{L})$ & A & 0.05 & 0.15 & 0.14 & 0.02 & 0.09 & 0.13 & 0.14 & 0.02 & 0.68 & 0.03 & 0.54 \\
\hline HOMA-IR (AU) & A & 0.26 & 0.90 & 0.82 & 0.12 & 0.55 & 0.75 & 0.85 & 0.12 & 0.75 & 0.04 & 0.44 \\
\hline \multicolumn{13}{|c|}{ Metabolites (mmol/L) } \\
\hline \multirow[t]{2}{*}{ Glucose } & A & 4.93 & 5.57 & 5.26 & 0.14 & 5.22 & 5.15 & 5.34 & 0.14 & 0.93 & 0.28 & 0.16 \\
\hline & $\mathrm{HV}$ & 5.81 & 5.93 & 5.74 & 0.38 & 5.74 & 5.71 & 6.57 & 0.33 & 0.72 & 0.22 & 0.07 \\
\hline \multirow[t]{2}{*}{ Lactate } & A & 0.42 & 0.62 & 0.68 & 0.02 & 0.44 & 0.58 & 0.72 & 0.02 & 0.76 & $<0.001$ & 0.70 \\
\hline & $\mathrm{HV}$ & 0.50 & 0.64 & 0.74 & 0.05 & 0.44 & 0.80 & 0.94 & 0.04 & 0.14 & $<0.001$ & 0.17 \\
\hline \multirow[t]{2}{*}{ Urea } & A & 4.30 & 3.78 & 3.94 & 0.17 & 4.15 & 3.60 & 3.56 & 0.18 & 0.36 & 0.10 & 0.90 \\
\hline & $\mathrm{HV}$ & 4.40 & 3.74 & 4.14 & 0.24 & 4.23 & 3.66 & 3.53 & 0.21 & 0.39 & 0.16 & 0.67 \\
\hline \multirow[t]{2}{*}{ Ammonia } & $\mathrm{A}$ & 42.1 & 44.0 & 42.2 & 5.6 & 36.3 & 37.7 & 45.0 & 5.6 & 0.70 & 0.65 & 0.58 \\
\hline & $\mathrm{HV}$ & 61.7 & 52.9 & 58.6 & 7.9 & 46.3 & 39.4 & 52.6 & 6.9 & 0.28 & 0.21 & 0.70 \\
\hline \multirow[t]{2}{*}{$\beta$-hydroxybutyrate } & $\mathrm{A}$ & 11.5 & 8.1 & 8.8 & 0.8 & 14.8 & 7.2 & 7.3 & 0.8 & 0.80 & 0.01 & 0.32 \\
\hline & $\mathrm{HV}$ & 15.0 & 10.8 & 11.4 & 2.3 & 24.5 & 10.6 & 13.3 & 1.9 & 0.24 & 0.03 & 0.33 \\
\hline \multirow[t]{2}{*}{ Acetate } & $\mathrm{A}$ & 613 & 755 & 679 & 15 & 664 & 658 & 664 & 15 & 0.37 & 0.11 & 0.08 \\
\hline & $\mathrm{HV}$ & 692 & 886 & 786 & 32 & 819 & 931 & 880 & 28 & 0.06 & 0.04 & 0.76 \\
\hline \multirow[t]{2}{*}{ Propionate } & $\mathrm{A}$ & 20.7 & 27.4 & 22.1 & 0.6 & 22.6 & 23.3 & 20.3 & 0.6 & 0.13 & 0.01 & 0.11 \\
\hline & $\mathrm{HV}$ & 27.3 & 31.1 & 27.7 & 3.3 & 25.5 & 36.7 & 33.1 & 2.9 & 0.50 & 0.39 & 0.75 \\
\hline \multirow[t]{2}{*}{ Butyrate } & $\mathrm{A}$ & 2.97 & 5.45 & 5.40 & 0.75 & 3.15 & 5.01 & 2.53 & 0.75 & 0.34 & 0.13 & 0.37 \\
\hline & $\mathrm{HV}$ & 8.53 & 9.04 & 7.69 & 1.72 & 8.15 & 12.8 & 9.19 & 1.50 & 0.48 & 0.14 & 0.36 \\
\hline \multirow[t]{2}{*}{$\Sigma$ SCFA } & $\mathrm{A}$ & 636 & 788 & 707 & 16 & 689 & 687 & 687 & 16 & 0.34 & 0.09 & 0.08 \\
\hline & $\mathrm{HV}$ & 728 & 926 & 822 & 34 & 853 & 981 & 922 & 29 & 0.06 & 0.04 & 0.82 \\
\hline \multicolumn{13}{|c|}{ Amino acids (mmol/L) } \\
\hline \multirow[t]{2}{*}{ Leucine } & A & 177 & 193 & 211 & 8 & 171 & 183 & 211 & 9 & 0.65 & 0.01 & 0.90 \\
\hline & $\mathrm{HV}$ & 172 & 200 & 224 & 9 & 176 & 196 & 214 & 8 & 0.76 & 0.03 & 0.91 \\
\hline \multirow[t]{2}{*}{ Isoleucine } & $\mathrm{A}$ & 126 & 157 & 144 & 7 & 119 & 157 & 147 & 7 & 0.90 & 0.004 & 0.88 \\
\hline & $\mathrm{HV}$ & 126 & 162 & 148 & 8 & 121 & 165 & 149 & 7 & 0.95 & 0.01 & 0.94 \\
\hline
\end{tabular}


Table 2. Cont.

\begin{tabular}{|c|c|c|c|c|c|c|c|c|c|c|c|c|}
\hline & & \multicolumn{4}{|c|}{$\mathbf{O}$} & \multicolumn{4}{|c|}{$\mathrm{O}+\mathrm{F}$} & \multicolumn{3}{|c|}{$p$ Value } \\
\hline & & D1 & D14 & D56 & SEM & D1 & D14 & D56 & SEM & Diet & Time & Diet $\times$ Time \\
\hline \multirow[t]{2}{*}{ Valine } & $\mathrm{A}$ & 324 & 314 & 362 & 11 & 314 & 313 & 365 & 12 & 0.85 & 0.04 & 0.94 \\
\hline & $\mathrm{HV}$ & 308 & 314 & 386 & 9 & 317 & 317 & 378 & 8 & 0.97 & 0.04 & 0.91 \\
\hline \multirow[t]{2}{*}{ Lysine } & $\mathrm{A}$ & 166 & 165 & 156 & 8 & 163 & 163 & 177 & 8 & 0.62 & 0.96 & 0.39 \\
\hline & $\mathrm{HV}$ & 166 & 168 & 157 & 9 & 155 & 163 & 172 & 8 & 0.95 & 0.91 & 0.57 \\
\hline \multirow[t]{2}{*}{ Phenylalanine } & $\mathrm{A}$ & 64.1 & 71.3 & 77.2 & 3.4 & 63.4 & 65.3 & 76.7 & 3.5 & 0.63 & 0.005 & 0.66 \\
\hline & $\mathrm{HV}$ & 59.1 & 69.1 & 76.3 & 3.6 & 61.7 & 65.2 & 72.1 & 3.2 & 0.70 & 0.002 & 0.50 \\
\hline \multirow[t]{2}{*}{ Methionine } & $\mathrm{A}$ & 22.4 & 26.8 & 25.2 & 1.9 & 22.9 & 29.4 & 25.1 & 2.0 & 0.72 & 0.03 & 0.77 \\
\hline & $\mathrm{HV}$ & 21.3 & 26.4 & 21.9 & 1.8 & 22.1 & 30.2 & 25.0 & 1.6 & 0.31 & 0.004 & 0.70 \\
\hline \multirow[t]{2}{*}{ Threonine } & $\mathrm{A}$ & 156 & 161 & 166 & 8 & 164 & 164 & 172 & 9 & 0.65 & 0.57 & 0.94 \\
\hline & $\mathrm{HV}$ & 142 & 156 & 167 & 7 & 158 & 156 & 167 & 6 & 0.59 & 0.23 & 0.65 \\
\hline \multirow[t]{2}{*}{ Tryptophane } & $\mathrm{A}$ & 51.6 & 53.9 & 45.8 & 3.1 & 49.2 & 58.3 & 49.5 & 3.2 & 0.68 & 0.17 & 0.71 \\
\hline & $\mathrm{HV}$ & 52.5 & 59.3 & 49.0 & 4.6 & 51.4 & 56.8 & 48.4 & 4.1 & 0.83 & 0.17 & 0.98 \\
\hline \multirow[t]{2}{*}{ Histidine } & A & 90.0 & 101.6 & 104.3 & 4.6 & 91.8 & 100.6 & 108.0 & 4.7 & 0.82 & $<0.001$ & 0.76 \\
\hline & $\mathrm{HV}$ & 90.7 & 100.9 & 100.0 & 4.8 & 90.6 & 102.1 & 108.1 & 4.3 & 0.64 & $<0.001$ & 0.33 \\
\hline \multirow[t]{2}{*}{ Alanine } & $\mathrm{A}$ & 210 & $280 a$ & $238 a$ & 12 & 206 & $325 b(t)$ & $296 b$ & 12 & 0.07 & $<0.001$ & 0.22 \\
\hline & $\mathrm{HV}$ & 190 & $240 a$ & $192 a$ & 16 & 172 & $309 b$ & $270 b$ & 14 & 0.06 & 0.003 & 0.10 \\
\hline \multirow[t]{2}{*}{ Glutamate } & $\mathrm{A}$ & 127 & 182 & 154 & 12 & 114 & 167 & 189 & 13 & 0.90 & $<0.001$ & 0.17 \\
\hline & $\mathrm{HV}$ & 218 & 321 & 358 & 52 & 221 & 357 & 402 & 46 & 0.69 & $<0.001$ & 0.79 \\
\hline \multirow[t]{2}{*}{ Glutamine } & $\mathrm{A}$ & 357 & 375 & 373 & 22 & 378 & 400 & 390 & 23 & 0.52 & 0.44 & 0.97 \\
\hline & $\mathrm{HV}$ & 329 & 363 & 277 & 24 & 324 & 329 & 328 & 22 & 0.90 & 0.07 & 0.08 \\
\hline \multirow[t]{2}{*}{ Glycine } & $\mathrm{A}$ & 801 & 982 & 849 & 38 & 865 & 1036 & 880 & 39 & 0.38 & 0.002 & 0.94 \\
\hline & $\mathrm{HV}$ & 819 & 1008 & 823 & 53 & 852 & 994 & 885 & 47 & 0.71 & 0.03 & 0.82 \\
\hline \multirow[t]{2}{*}{ Proline } & $\mathrm{A}$ & 308 & 338 & 297 & 8 & 295 & 347 & 325 & 8 & 0.49 & 0.13 & 0.63 \\
\hline & $\mathrm{HV}$ & 308 & 316 & 299 & 16 & 292 & 333 & 361 & 14 & 0.36 & 0.52 & 0.37 \\
\hline \multirow[t]{2}{*}{ Tyrosine } & $\mathrm{A}$ & 82.9 & 89.0 & 86.4 & 8.0 & 78.4 & 90.3 & 87.6 & 8.2 & 0.96 & 0.18 & 0.79 \\
\hline & $\mathrm{HV}$ & 79.0 & 87.5 & 88.3 & 9.8 & 72.3 & 86.7 & 79.5 & 8.7 & 0.68 & 0.12 & 0.71 \\
\hline \multirow[t]{2}{*}{ Serine } & $\mathrm{A}$ & 128 & 176 & 164 & 7 & 144 & 186 & 177 & 7 & 0.20 & $<0.001$ & 0.94 \\
\hline & $\mathrm{HV}$ & $113 a$ & 168 & 156 & 7 & $145 b$ & 175 & 167 & 6 & 0.10 & $<0.001$ & 0.16 \\
\hline \multirow[t]{2}{*}{ Arginine } & $\mathrm{A}$ & 107 & 126 & 126 & 4 & 111 & 126 & 140 & 4 & 0.29 & 0.003 & 0.51 \\
\hline & $\mathrm{HV}$ & 106 & 128 & 122 & 5 & 109 & 124 & 151 & 4 & 0.17 & 0.01 & 0.12 \\
\hline \multirow[t]{2}{*}{ Citrulline } & $\mathrm{A}$ & 82.8 & $85.0 a$ & 86.2 & 4.1 & 77.9 & $103.1 b(t)$ & 97.5 & 4.6 & 0.20 & 0.03 & 0.09 \\
\hline & $\mathrm{HV}$ & 94.3 & 109.4 & 104.8 & 6.8 & 89.5 & 127.6 & 116.3 & 6.4 & 0.36 & $<0.001$ & 0.11 \\
\hline Cystine & $\mathrm{A}$ & 75.0 & 54.8 & 56.2 & 2.0 & 72.8 & 59.5 & 64.0 & 2.1 & 0.26 & 0.002 & 0.54 \\
\hline & $\mathrm{HV}$ & 80.5 & 51.9 & 57.5 & 2.2 & 75.7 & 61.4 & 63.5 & 2.0 & 0.27 & 0.008 & 0.51 \\
\hline Ornithine & $\mathrm{A}$ & 72.4 & 95.6 & $69.4 a$ & 2.4 & 68.8 & $90.7 b(t)$ & 80.2 & 2.5 & 0.84 & $<0.001$ & 0.10 \\
\hline & $\mathrm{HV}$ & 83.9 & 98.2 & 74.5 & 3.4 & 72.7 & 94.2 & 85.0 & 3.0 & 0.74 & $<0.001$ & 0.07 \\
\hline Asparagine & $\mathrm{A}$ & 18.7 & 35.6 & 21.1 & 2.9 & 19.4 & 30.2 & 23.5 & 2.9 & 0.86 & 0.003 & 0.56 \\
\hline & $\mathrm{HV}$ & 18.1 & 34.3 & 17.2 & 4.8 & 7.9 & 16.8 & 12.1 & 4.3 & 0.11 & 0.03 & 0.39 \\
\hline Aspartate & $\mathrm{A}$ & 8.6 & 12.4 & 8.4 & 0.97 & 7.3 & 12.1 & 9.5 & 1.0 & 0.91 & 0.002 & 0.62 \\
\hline & $\mathrm{HV}$ & 10.0 & 13.2 & 10.4 & 1.3 & 9.8 & 15.9 & 12.8 & 1.2 & 0.38 & 0.01 & 0.55 \\
\hline Taurine & PV & 104 & $155 a$ & 117 & 9 & 95 & 116 & $108 b$ & 10 & 0.15 & 0.001 & 0.10 \\
\hline & $\mathrm{HV}$ & 109 & 136 & 108 & 8 & 106 & 118 & 106 & 7 & 0.44 & 0.002 & 0.25 \\
\hline LBP (ng/L) & $\mathrm{A}$ & 3.16 & 2.94 & 3.68 & 0.43 & 2.51 & 1.71 & 2.99 & 0.43 & 0.18 & 0.25 & 0.85 \\
\hline & PV & 3.07 & $3.02 a$ & 4.24 & 0.48 & 1.46 & $0.93 b(t)$ & 3.00 & 0.51 & 0.03 & 0.11 & 0.86 \\
\hline & VSH & 3.18 & 3.03 & 3.35 & 0.48 & 2.51 & 1.78 & 3.17 & 0.40 & 0.28 & 0.32 & 0.63 \\
\hline IL6 (pg/mL) & A & 5.09 & 4.90 & 5.45 & 0.45 & 4.23 & 4.29 & 5.95 & 0.46 & 0.62 & 0.20 & 0.57 \\
\hline
\end{tabular}

Values are means $p$-values and were obtained by Two Way Repeated Measures ANOVA. For a metabolite, within the same time point, O and $\mathrm{O}+\mathrm{F}$ are significantly different $(a, b)$ or tend $(t)$ to be different.

\subsection{Fecal SCFAs Concentration}

Although SCFAs concentration in the artery was not altered by fibre supplementation, it was not the case within the lumen of the gut. Figure 3A shows the evolution of SCFAs concentrations in fecal water expressed as a percentage of the concentration measured at D1. During the experimental period (D14 and D56), total SCFAs in the feces $(\mu \mathrm{mol} / \mathrm{g}$ feces) increased by $52 \pm 16 \%$ in the F group, whereas it remained stable $(+2.9 \pm 16 \%)$ in the $\mathrm{O}$ group relative to the concentration of SCFAs at D0 (Diet effect, $p=0.05$ ). Acetate content 
increase was more pronounced in the $\mathrm{O}+\mathrm{F}$ than $\mathrm{O}$ group in both D14 and D56 (Diet effect, $p=0.06$ ) (Figure 3A). Propionate and butyrate followed the same pattern of change (Diet effect, $p=0.05$ and $p=0.08$ for propionate and butyrate, respectively) (Figure 3A).

\subsection{Fasting Nutrient Net Fluxes across the Splanchnic Area}

The net portal drained viscera release of acetate (Diet effect, $p=0.11$ ), and the net splanchnic release of acetate were not affected (Diet effect, $p=0.13$ ) (Figure 3B). Contrary to acetate, a trend (Diet $\times$ time effect, $p<0.1$ ) for an increased net release of propionate and butyrate in the portal vein of fibre-supplemented animals occurred at $\mathrm{D} 14(\mathrm{O}+\mathrm{F}$ vs. $\mathrm{O}$, $p=0.04$ and $p=0.03$ for propionate and butyrate, respectively, post hoc analysis), but was no longer significant at D56 (Figure 3B). This occurred simultaneously with a numerically increased net hepatic uptake of propionate and butyrate at D14, even if not significant. At the overall splanchnic level, no significant differences on propionate and butyrate net release were found over the entire experimental period. In addition, the presence of these three major SCFAs in fecal water decreased over time independent of fibre supplementation (Time effect, $p=0.007, p=0.002, p=0.025$ for acetate, propionate and butyrate, respectively), and similar patterns, although not always significant, were described for portal drained viscera, liver and total splanchnic fluxes, especially in the $\mathrm{O}+\mathrm{F}$ group.

\section{A SCFA content in the fecal water $(\mu \mathrm{mol} / \mathrm{g}$ wet feces, expressed as a percentage of the quantity at $D 1$ )}

$\mathrm{O}$
$\mathrm{O}+\mathrm{F}$

Acetate

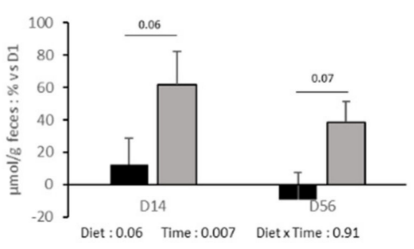

Propionate

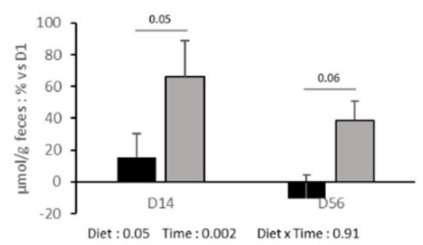

Butyrate

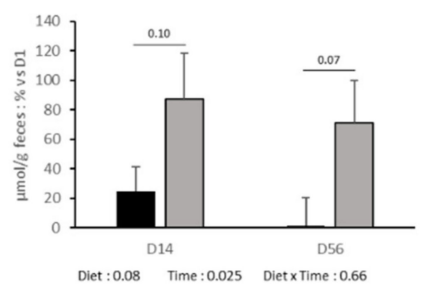

B SCFA net utilization by splanchnic tissues (net fluxes: $\mathrm{mol} / \mathrm{h}$ )

Portal drained viscera

Liver

Total splanchnic
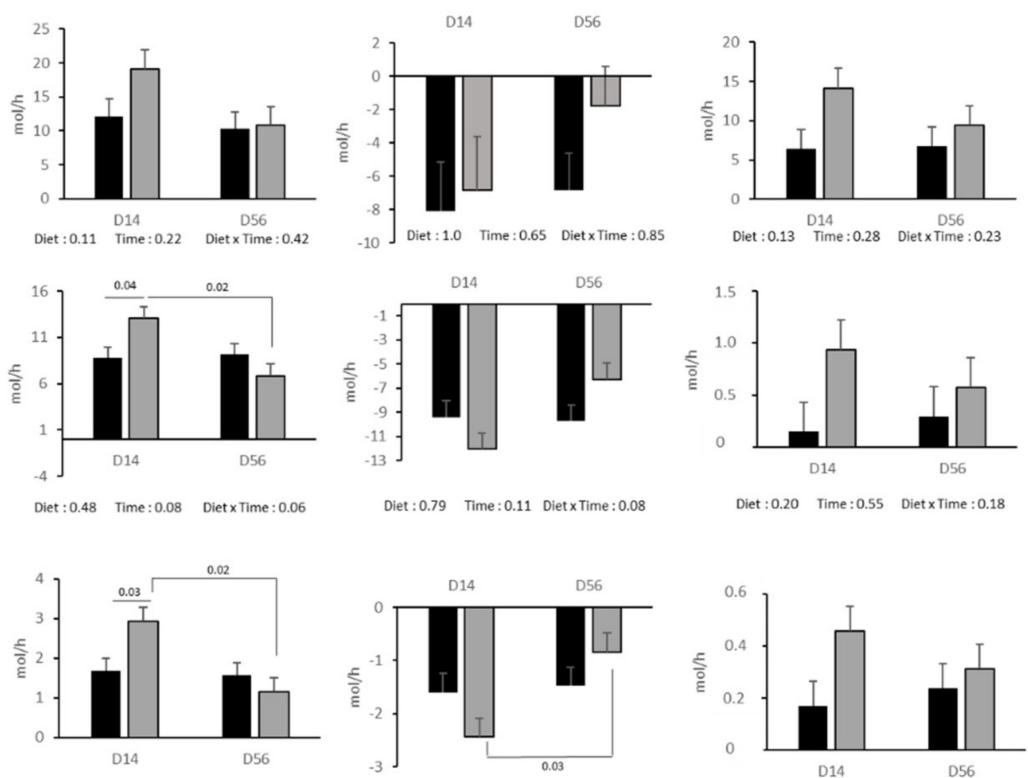

Diet $: 0.25$ Time $: 0.06$ Diet $x$ Time $: 0.09$

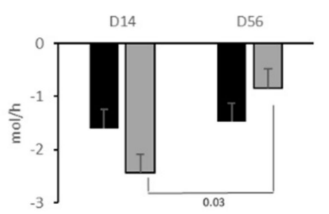

Diet $: 0.80$ Time $: 0.08$ Diet $x$ Time $: 0.12$

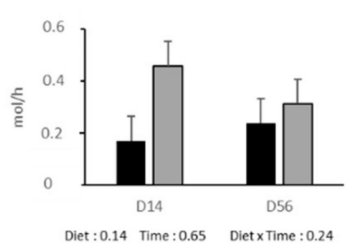

Figure 3. Short chain fatty acids (SCFA) (acetate, propionate and butyrate). (A) Concentration in the fecal water ( $\mu \mathrm{mol} / \mathrm{g}$ wet feces) expressed as a percentage of the quantity at the beginning of the experimental period (D1). (B) Net flux across the splanchnic tissues (mol/h) (portal drained viscera (PDV), liver, and total splanchnic tissues (TSP: PDV + liver) after 14 (D14) and 56 (D56) days of overnutrition $(\mathrm{O})$ or overnutrition and supplementation with a mix of dietary fibres $(\mathrm{O}+\mathrm{F})$. Data are expressed as the mean \pm S.E.M. Significant differences are considered when $p<0.05$.

For glucose and lactate, the fibre supplementation did not impact on their net gut release in the portal vein (Figure 4). On the contrary, a significant Diet and Time $\times$ Diet effect for glucose $(p<0.05)$ and Diet effect $(p=0.06)$ for lactate were observed in the liver. Net hepatic release was increased by fibre supplementation at D56 for glucose $(+320 \%$, $p=0.01)$ and D14 for lactate $(\times 17.9, p=0.04)$. In addition, a Time effect $(p=0.001)$ within the fibre-supplemented group was also observed for glucose release. The consequence was 
an increased net release of glucose and lactate by the overall splanchnic tissues in the fibresupplemented animals, especially at D56 for glucose (Diet $\times$ Time effect, $p=0.04$ ) and at D14 and a lesser extent D56 for lactate (Diet effect, $p=0.005$ ).

The fibre supplementation had no effect on net urea uptake (recycling) by the gut (net PDV uptake was similar between $\mathrm{O}$ and $\mathrm{O}+\mathrm{F}$ ), net hepatic release and net overall splanchnic release. For other metabolites (ammonia, BHB and individual AA), net PDV, hepatic and TSP fluxes were not strongly modified (no significant Diet or Diet $\times$ Time effects observed) by fibre supplementation (Supplementary Table S1).

Net utilization of glucose, lactate and urea by splanchnic tissues (net fluxes : $\mathrm{mmol} / \mathrm{h}$ )

$\square \stackrel{0}{0+F}$

Glucose

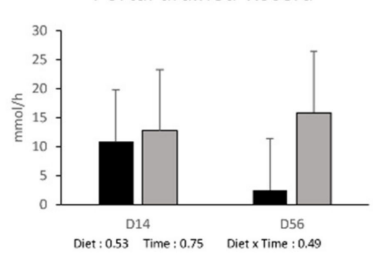

Diet: 0.53 Time: 0.75 Diet $\times$ Time : 0.00

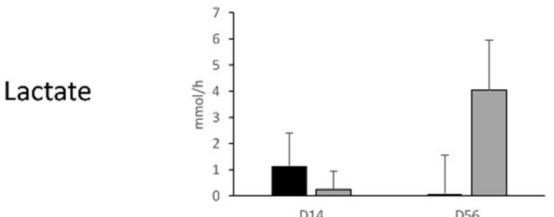

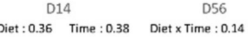

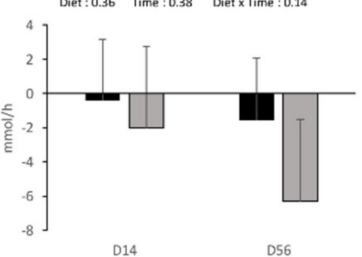

$\begin{array}{ccc}\text { D14 } & & \text { D56 } \\ \text { Diet }: 0.45 & \text { Time }: 0.67 & \text { Diet x Time }: 0.71\end{array}$

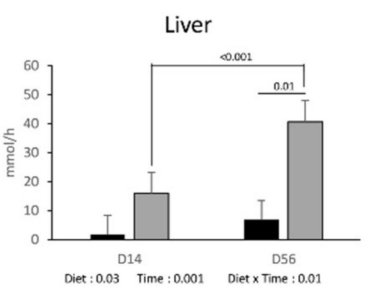

Diet : 0.03 Time $: 0.001$ Diet $x$ Time : 0.01
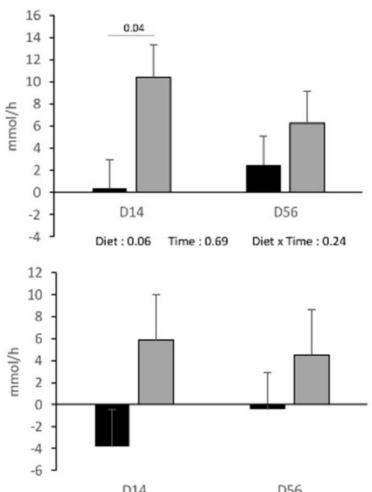

$\begin{array}{ccc}\text { D14 } & & \text { D56 } \\ \text { Diee: } 0.19 & \text { Time }: 0.72 & \text { Diet x Time : } 0.43\end{array}$
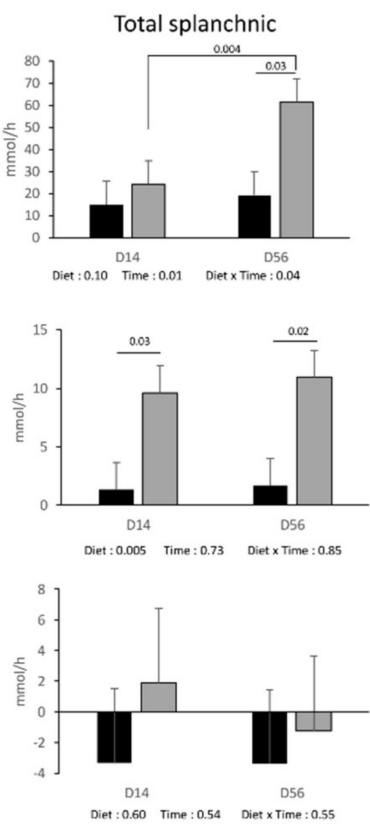

Figure 4. Glucose, lactate and urea net fluxes $(\mathrm{mmol} / \mathrm{h})$ (across the splanchnic tissues (portal drained viscera (PDV), liver, and total splanchnic tissues (PDV + liver) TSP)) after 14 (D14) and 56 (D56) days of overnutrition (O) or overnutrition and supplementation with a mix of dietary fibres $(\mathrm{O}+\mathrm{F})$. Data are expressed as the mean \pm S.E.M. Significant differences are considered when $p<0.05$.

\section{Discussion}

The aim of the present study was to explore, in the fasted state, the inter-organ crosstalk between gut, liver, muscle and adipose tissue on nutrients utilization and handling in order to explain the metabolic effects of fibre supplementation on peripheral tissues after adaptation to overnutrition in adult mini-pigs. Briefly, net splanchnic release of glucose and lactate increased when fibres were supplemented. In such situation, lipid entry and storage within the liver was also limited, as already published elsewhere [13]. This suggests that energy storage and utilization by the splanchnic area (and notably the liver) was decreased by fibre supplementation. Accordingly, we observed specific metabolic adaptations to this overall increased energy supply at the peripheral level, such as an increased capacity for fatty acid oxidation and mitochondrial activity in muscle and a raised fatty acids utilization and buffering capacity in adipose tissue, in fibre-supplemented mini-pigs.

\subsection{Overfeeding and Fibre Supplementation: Impact on Muscle Structure and Metabolic Activities}

Structural and phenotypic changes were observed at the muscle level (Longissimus dorsi) both after overnutrition and fibre supplementation. Of note, the increased average of muscle fibre CSA observed in animals from the $\mathrm{O}$ group is consistent with data already reported in obese humans [39-41] and Ossabaw pigs fed high fat/high cholesterol/high fructose [42] or Yucatan pigs fed a western diet [43]. This increased fibre CSA positively 
correlates with obesity and could be explained by a higher number of intramyocellular lipid droplets, as previously shown [42]. However, muscle triglycerides content remained unaltered after overfeeding in our study. The higher muscle fibre CSA in our O animals could be also due to a higher proportion of type II muscle fibres (lower size and glucose handling capacity) in detriment of highly-oxidative type I fibres, a feature associated with obesity in the literature [42,44]. Then, our data suggest that obesity-related alteration of muscle fibre CSA occurs before any impairments of lipid profile in the muscle.

This difference in muscle phenotype observed in our overfed fibre-supplemented pigs relative to overfed non-supplemented animals was also true metabolically as an increased capacity for fatty acids oxidation and an activation of mitochondrial activity was suggested by the gene overexpression of acox, sdha, ucp 2 and cpt1-m in $\mathrm{O}+\mathrm{F}$ vs. $\mathrm{O}$ and $\mathrm{C}$. This increased capacity for fatty acids catabolism and mitochondrial activity in the muscle, potentially leading to an increased utilization of lipids, can be one of the explanations why the liver remained relatively protected from an exacerbated lipids storage in dietary fibre-supplemented animals [13]. Such an up-regulation of muscle genes expression and enzymes involved in fatty acid oxidation and mitochondrial activity has been shown in rodents both after specific soluble fibres (i.e., Psyllum or epilactose) [22,45] or butyrate [21] supplementation when the animals were fed a high fat diet and developed obesity. In our case, the intake of a reasonable amount of a fibre-rich and ready-to-consume formulated bread was capable to switch muscle metabolism towards lipids utilization in an overfed mini-pigs model, suggesting that such a nutritional strategy could be transferable to humans. A mitochondrial dysfunction and a reduction of oxidative capacities in the muscle of obese and insulin-resistant volunteers/models have been repeatedly demonstrated [46,47], thus targeting mitochondrial dysfunction (as could be the case with dietary fibre supplementation) might improve muscle insulin signaling [48]. The pathway of lipid catabolism could also be fueled by a mobilization of fats within the muscle as suggested by an increased expression of the hydrolase $h s l$ in fibre mix-supplemented animals, as already observed in muscle during exercise (i.e., when energy demand within the muscle is also stimulated) [49]. The existence of such a mechanism within the muscle of dietary fibresupplemented animals, where muscle mitochondrial activity is also stimulated, requires to be further investigated. The triglyceride content within the muscle, similar within the three groups of animals cannot help to validate or invalidate this hypothesis.

A controller of energy metabolism/mitochondrial function in our study, $p g c-1 \alpha$ significantly increased in the dietary fibre-supplemented group vs. O and $\mathrm{C}$, and is a good candidate to modulate and stimulate energy catabolism. First, $p g c-1 \alpha$ is known to be down-regulated during the development of insulin resistance, obesity and mitochondrial dysfunction [50,51] in parallel with $p g c-1 \alpha$ target/associated genes: nrf1, nrf2 or ppar $\alpha[21,50,51]$. Moreover, down-regulation of $p g c-1 \alpha$ specifically in muscle favors chronic inflammation that, in turn, is closely associated to the production of reactive oxygen species (ROS) [52]. On the contrary, $p g c-1 \alpha$ is generally up-regulated by butyrate or fibre supplementation $[21,45,53]$ even if not always [54]. In the present study, together with the increased $p g c-1 \alpha$ mRNA expression, associated genes $n r f 2$ and ppar $\alpha$ [51] were significantly increased in muscle following fibre supplementation. Particularly, $n r f 2$ is known to respond to the increased ROS production by the activated mitochondria and oxidation processes [55]. In addition, transgenic mice overexpressing ppar $\alpha$ in muscle exhibited increased fatty acid oxidation rates and were protected against diet-induced obesity [56]. Lastly, a link can be hypothesized between $p g c-1 \alpha$ and fibre sizes: $p g c-1 \alpha$ is known to be more expressed in muscles rich in type I fibres, which means that an enrichment in oxidative fibres in $\mathrm{O}+\mathrm{F}$ animals can be hypothesized in our pigs' muscles and explain the relatively smaller fibre area (lower average CSA) observed in $\mathrm{O}+\mathrm{F}$ animals vs. $\mathrm{O}$, since a higher oxidative capacity is generally associated with a lower fibre size in muscle [57].

In the present study, and contrary to what is generally found in the literature [58], the increased lipid oxidation does not seem to be associated with an increased stimulation of systems involved in lipids entry within the cell, as shown by the absent differences 
in the slc27a4 (coding for FATP4) gene expression between $\mathrm{O}$ and $\mathrm{O}+\mathrm{F}$. However, lipid transporters, and among them slc27a4, are known to be regulated by complex translocation mechanisms [59], and not solely by transcriptional regulations. This means that an increased lipid entry within the cells following fibre supplementation in our situation of overfeeding cannot be entirely excluded, even if not measured.

\subsection{Overfeeding and Fibre Supplementation: Impact on Adipose Tissue mRNA Levels}

Such as for muscle, an increased lipids oxidation can be hypothesized in the subcutaneous adipose tissue of fibre-supplemented animals as suggested by an increased cpt1 expression, the rate-limiting enzyme in mitochondrial fatty acid $\beta$-oxidation. In addition, the fact that ppar $\alpha$ was also more stimulated in animals supplemented with the mix of fibres, sustains the hypothesis of an increased lipid catabolism in the adipose tissue. A stimulated fatty acids oxidation in adipose tissues has been reported in animal models following SCFAs or fibre supplementation [24,60], with a switch from lipogenesis to fat oxidation [24]. However, in our case, the impact of fibres on this pathway is not as straightforward because other genes expression (acox, cpt2, sdha, and ucp2) involved in mitochondrial activities or lipids catabolism are not differentially modulated in fibre-supplemented animals relative to $\mathrm{O}$.

Lipid synthesis in the adipose tissues is stimulated by energy overload in overfed animals (supplemented or not with fibres), as shown by fasn gene expression up-regulation, thus suggesting that regulatory mechanisms of lipids handling following dietary fibre supplementation is more focused on the stimulation of catabolism than inhibition of synthesis. However, and contrarily to muscles, where an increased hsl gene expression in $\mathrm{O}+\mathrm{F}$ animals tended to limit lipids storage as triglycerides and increase lipolysis within the muscle, no such specific regulatory mechanisms exist in adipose tissues as $h s l \mathrm{mRNA}$ levels remained unaltered whatever the diet considered. Concerning the lipid storage capacity via extracellular lipolysis mediated by lipoprotein lipase (hsl), the story is different because angptl4 gene expression, an inhibitor of LPL, was down-regulated in the fibresupplemented group. Therefore, an hypothesized increased LPL activity (due to a lack of inhibition of angptl4) in the $\mathrm{O}+\mathrm{F}$ group might increase the buffering capacity of the adipose tissues by increasing LPL-mediated triglycerides extraction, clearance of triacylglycerol, and whole body insulin sensitivity [16], as also shown in angptl4 $\mathrm{KO}$ mice [61]. In fact, an increased insulin sensitivity at the adipose level in fibre-supplemented animals can be expected as insulin is known to reduce angptl4 gene expression in mice adipocytes [62]. This metabolic adaptation could prevent lipid deposition in other tissues, and notably liver, as already shown in a previous work [13]. As no alteration of plasma triglycerides or free fatty acids concentrations was observed throughout the experimental period of overfeeding, this hypothesis should require further investigation [13].

\subsection{Consequences of the Activation of Lipid Catabolism in the Peripheral Organs on Overall Energy Metabolism}

The metabolite $\beta$-OH-butyrate (BHB) can be synthesized from fatty acids (i.e., butyrate) [63] both in the gut or in the liver. At the hepatic level, we have already demonstrated an absence of impact of dietary fibre supplementation in overfed animals on fatty acid oxidation [13], therefore suggesting an unaltered hepatic BHB production rate. In line with these results, circulating levels of BHB were not altered by fibre supplementation. However, the increased butyrate levels present in the fecal water from fibre-supplemented animals suggested a potentially increased gut release of BHB to the periphery, as shown after butyrate infusion by Fitch et al. [63]. To explain this apparent discrepancy, the relative importance of $\mathrm{BHB}$ production at the gut level relative to $\mathrm{BHB}$ production from the betaoxidation process in the liver to the final circulating BHB available to peripheral tissues should be much lower.

Nevertheless, the fibre-induced increase of lipid catabolism at the peripheral level might have generated an increased acetyl-CoA flux and pool size and the consequent activation of the Krebs cycle in muscle. As acetyl-CoA is known to inhibit pyruvate de- 
hydrogenase kinase [64], accumulated pyruvate (from glycolysis) is redirected towards reduction into lactate and transamination into alanine in the muscle [65]. Therefore, the increased muscle lipids catabolism may induce a channeling of muscle acetyl-CoA towards Krebs cycle in the $\mathrm{O}+\mathrm{F}$ animals, whereas pyruvate utilization is shifted from acetyl-CoA synthesis (from PDH activity) to alanine synthesis [66] and stimulation of the alanine-glucose cycle [67] at the whole body level. The tendency for an increased plasma concentration of alanine in artery and hepatic veins of overfed fibre-supplemented animals compared to overfed non-supplemented animals supports a preferred utilization of pyruvate towards synthesis of alanine in the muscle, whereas alanine is used for gluconeogenesis at the hepatic level (as observed with the increased net hepatic glucose production (Figure 2). Unfortunately, due to a high variability of the data, no significant increased alanine uptake was observed at the hepatic level to definitely validate this hypothesis of increased hepatic alanine utilization for glucose synthesis (Supplementary Table S1).

\subsection{Mediators of These Metabolic Adaptation to Fibre Supplementation}

Most of the studies have hypothesized the role of SCFAs as mediators of the beneficial effect of fibres on metabolism because in nearly all cases of fibre supplementation, there is an increase in fecal SCFA concentration $[16,68]$. Additionally, some of these studies reported an increased circulating SCFA content in the portal vein in animals supplemented with dietary fibres $[69,70]$, with sometimes but not always an impact at the peripheral level as well [71]. Several authors have proven the role of fermentation products of fibres in the gut as mediators of the metabolic responses [16,21], with direct infusion/ingestion of SCFA in vivo [21] or in vitro on cell culture [72]. In the present study, we questioned the role of SCFAs as direct regulators of metabolic adaptations to overfeeding at the peripheral level as we failed to show significant alterations of net splanchnic emission of acetate, propionate and butyrate even if their concentrations were increased in fecal water. Part of this observation can arise from the fact that all measurements were made in the fasted state, whereas maximum production peak of SCFAs may arise within the first ten hours post meal ingestion, a factor that depends on the nature of fibres that reach the colon [73]. Aside from this "timing" effect, SCFAs produced from dietary fibres may have an indirect effect by inducing signals at the local level (i.e., gut level and hepatic level), as SCFAs receptors in the caecum (gpr41) and gut peptides synthesis in the jejunum $(g c g)$ were up-regulated in fibre-supplemented animals compared to the O group. Remarkably, gcg gene encodes for a preprotein cleaved in four different peptides and among them GLP-1 and 2, which are involved in the regulation of gut growth and insulin sensitivity and secretion [74-76]. These peptides could take over the role of SCFAs at the peripheral level and should require further investigation as potential mechanisms of regulation of muscle/adipose tissue mitochondrial metabolic activity by dietary fibres. On the other hand, the timedependent decrease of SCFAs concentrations reported in fecal water, independent of fibre supplementation, might be reflecting the potential deleterious impact of overfeeding to the gut microbiota composition and/or its capacity to generate these fermentation endproducts. Hence, these results question the efficiency of fibre supplementation on health parameters on a long-term basis.

An increased sensitivity of peripheral tissues to similar amounts of SCFAs cannot be entirely excluded. Indeed, the overfeeding-induced decrease in GPR43 expression levels, a G-protein coupled receptor activated by SCFAs, was reverted by fibre supplementation in the adipose tissue. This is not the case in muscle, where the same gene is significantly downregulated by overfeeding but not differentially expressed between the $\mathrm{O}$ and $\mathrm{O}+\mathrm{F}$ groups (1.65 \pm 0.67 vs. $1.50 \pm 0.50, p=0.695)$. Lastly, other molecules issued from catabolism of fibres within the caecum and colon and discussed in the literature could also be involved as regulatory molecules of energy metabolism and could improve insulin sensitivity of the host, such as succinate [77] or odd-chain fatty acids [78]. These potential effectors should be examined in detail, particularly via targeted (for succinate and odd-chain fatty acids) 
or untargeted (for still unknown molecules) metabolomics approaches, especially in the caecal water, portal plasma and tissues [79].

\section{Conclusions}

Our findings unveil several fibre-induced metabolic shifts involving nutrients and energy utilization in both the splanchnic area and peripheral tissues in a situation of overnutrition. Remarkably, we reveal an increased capacity for fatty acids catabolism and mitochondrial activity in the muscle of dietary fibre-supplemented mini-pigs that occurred in parallel with a shift of muscle fibre CSA into a lean-like profile. Then, we suggest that these features could be protecting the liver from lipids accumulation, although the undergoing mechanisms must be further evaluated, especially when an increased lipids entry within the myocytes could not be entirely excluded. In the adipose tissue, fibre supplementation did not impact as straightforward as for muscle. However, an increased cpt1 expression, the rate-limiting enzyme in mitochondrial fatty acid $\beta$-oxidation, and a downregulated expression of LPL inhibitor angptl4, indicate a fibre-favored buffering capacity of adipose tissue by increasing triglycerides extraction and fatty acids utilization. Altogether, the fibre-induced increase of lipids catabolism at the peripheral level might be responsible for an increased alanine/glucose cycle, as supported by the higher levels of arterial plasma alanine and glucose net release by the liver. Among the main effectors of these metabolic adaptations, our data suggest that fibre-derived SCFAs are proposed to play a key role by locally signaling on up-regulated gastrointestinal targets (gpr41 and $g c g$ ), thus highlighting the fibre consumption as a nutritional solution to improve insulin sensitivity by up-regulating GLPs incretin production. On the contrary, the SCFAs' capacity to directly modulate energy storage and utilization at the peripheral level can be questioned. To conclude, the supplementation with a mix of dietary fibres favored the metabolic switch into lipid oxidation, especially in Longissimus dorsi, in overfed mini-pigs.

Supplementary Materials: The following are available online at https:/ / www.mdpi.com/article/10 $.3390 /$ nu13124202/s1, Table S1: Net flux (mmol/h) of ammonia, beta hydroxybutyrate (b-OH), the sum of the three short chain fatty acids ( $\triangle$ SCFA), and amino acids across the portal drained viscera (PDV), liver and total splanchnic tissues (TSP) in the fasted state after 14 (D14) and 56 (D56) days of nutritional treatment.

Author Contributions: Conceptualization, I.S.-A., S.P., D.R. and D.D.; methodology, A.B.M., D.R., A.B.-D., F.C., M.-C.M., F.L., B.C., N.H., D.B., C.C.-G., C.M., J.D., S.P. and I.S.-A.; validation, A.B.M., I.S.-A. and S.P., formal analysis: writing—original draft preparation: A.B.M., S.P., I.S.-A. and A.G.-G.; writing-review and editing, A.B.M., D.R., A.G.-G., A.B.-D., F.C., M.-C.M., F.L., B.C., N.H., D.B., C.C.-G., M.G., J.S., C.M., D.D., J.D., S.P. and I.S.-A.; funding acquisition, I.S.-A. All authors have read and agreed to the published version of the manuscript.

Funding: The project was supported by INRAE (AlimH, TRANSFORM and MICA research departments).

Institutional Review Board Statement: The study was conducted according to the guidelines of the Declaration of Helsinki, and approved by the Institutional Review Board of Comité d'Ethique Auvergne (C2EA \#2), protocol code C63 34514 (14 October 2014).

Informed Consent Statement: Not applicable.

Data Availability Statement: The data presented in this study are available on request from the corresponding author.

Acknowledgments: To Cargill ${ }^{\odot}$ for providing the dietary fibres (pectin, inulin and resistance starch). SCFAs analyses were performed within the MetaboHUB French infrastructure (ANR-INBS-0010). The authors acknowledge G Della-Valle and H Chiron for bread making and design as well as M. Jarzaguet, C. Buffière, J.P. Rigaudière, C. Buisson, E. Delmas and the staff of Animal facility (C. Delhomme, J. Hermet) for technical assistance.

Conflicts of Interest: The authors declare no conflict of interest. 


\section{References}

1. Hales, C.M.; Fryar, C.D.; Carroll, M.D.; Freedman, D.S.; Ogden, C.L. Trends in Obesity and Severe Obesity Prevalence in US Youth and Adults by Sex and Age, 2007-2008 to 2015-2016. JAMA J. Am. Med. Assoc. 2018, 319, 1723-1725. [CrossRef] [PubMed]

2. Afshin, A.; Forouzanfar, M.H.; Reitsma, M.B.; Sur, P.; Estep, K.; Lee, A.; Marczak, L.; Mokdad, A.H.; Moradi-Lakeh, M.; Naghavi, M.; et al. Health Effects of Overweight and Obesity in 195 Countries over 25 Years. N. Engl. J. Med. 2017, 377, 13-27. [CrossRef] [PubMed]

3. Weickert, M.O.; Pfeiffer, A.F.H. Impact of Dietary Fiber Consumption on Insulin Resistance and the Prevention of Type 2 Diabetes. J. Nutr. 2018, 148, 7-12. [CrossRef]

4. Brockman, D.A.; Chen, X.; Gallaher, D.D. Hydroxypropyl methylcellulose, a viscous soluble fiber, reduces insulin resistance and decreases fatty liver in Zucker Diabetic Fatty rats. Nutr. Metab. 2012, 9, 100. [CrossRef] [PubMed]

5. Threapleton, D.E.; Greenwood, D.C.; Evans, C.E.; Cleghorn, C.L.; Nykjaer, C.; Woodhead, C.; Cade, J.E.; Gale, C.P.; Burley, V.J Dietary fibre intake and risk of cardiovascular disease: Systematic review and meta-analysis. BMJ 2013, 347, f6879. [CrossRef]

6. Veronese, N.; Solmi, M.; Caruso, M.G.; Giannelli, G.; Osella, A.R.; Evangelou, E.; Maggi, S.; Fontana, L.; Stubbs, B.; Tzoulaki, I. Dietary fiber and health outcomes: An umbrella review of systematic reviews and meta-analyses. Am. J. Clin. Nutr. 2018, 107, 436-444. [CrossRef]

7. Dahl, W.J.; Stewart, M.L. Position of the Academy of Nutrition and Dietetics: Health Implications of Dietary Fiber. J. Acad. Nutr. Diet. 2015, 115, 1861-1870. [CrossRef]

8. Stephen, A.M.; Champ, M.M.; Cloran, S.J.; Fleith, M.; van Lieshout, L.; Mejborn, H.; Burley, V.J. Dietary fibre in Europe: Current state of knowledge on definitions, sources, recommendations, intakes and relationships to health. Nutr. Res. Rev. 2017, 30, 149-190. [CrossRef]

9. Saha, D.C.; Reimer, R.A. Long-term intake of a high prebiotic fiber diet but not high protein reduces metabolic risk after a high fat challenge and uniquely alters gut microbiota and hepatic gene expression. Nutr. Res. 2014, 34, 789-796. [CrossRef]

10. Jakobsdottir, G.; Xu, J.; Molin, G.; Ahrne, S.; Nyman, M. High-fat diet reduces the formation of butyrate, but increases succinate, inflammation, liver fat and cholesterol in rats, while dietary fibre counteracts these effects. PLoS ONE 2013, 8, e80476. [CrossRef]

11. Isken, F.; Klaus, S.; Osterhoff, M.; Pfeiffer, A.F.; Weickert, M.O. Effects of long-term soluble vs. insoluble dietary fiber intake on high-fat diet-induced obesity in C57BL/6J mice. J. Nutr. Biochem. 2010, 21, 278-284. [CrossRef] [PubMed]

12. Yan, H.; Potu, R.; Lu, H.; Vezzoni de Almeida, V.; Stewart, T.; Ragland, D.; Armstrong, A.; Adeola, O.; Nakatsu, C.H.; Ajuwon, K.M. Dietary fat content and fiber type modulate hind gut microbial community and metabolic markers in the pig. PLoS ONE 2013, 8, e59581. [CrossRef]

13. Mohamed, A.B.; Remond, D.; Chambon, C.; Sayd, T.; Hebraud, M.; Capel, F.; Cohade, B.; Hafnaoui, N.; Bechet, D.; CoudyGandilhon, C.; et al. A mix of dietary fermentable fibers improves lipids handling by the liver of overfed minipigs. J. Nutr. Biochem. 2018, 65, 72-82. [CrossRef] [PubMed]

14. Cummings, J.H.; Pomare, E.W.; Branch, W.J.; Naylor, C.P.; Macfarlane, G.T. Short chain fatty acids in human large intestine, portal, hepatic and venous blood. Gut 1987, 28, 1221-1227. [CrossRef] [PubMed]

15. Den Besten, G.; van Eunen, K.; Groen, A.K.; Venema, K.; Reijngoud, D.J.; Bakker, B.M. The role of short-chain fatty acids in the interplay between diet, gut microbiota, and host energy metabolism. J. Lipid Res. 2013, 54, 2325-2340. [CrossRef] [PubMed]

16. Canfora, E.E.; Jocken, J.W.; Blaak, E.E. Short-chain fatty acids in control of body weight and insulin sensitivity. Nat. Rev. Endocrinol. 2015, 11, 577-591. [CrossRef]

17. Lu, Y.; Fan, C.; Li, P.; Lu, Y.; Chang, X.; Qi, K. Short Chain Fatty Acids Prevent High-fat-diet-induced Obesity in Mice by Regulating G Protein-coupled Receptors and Gut Microbiota. Sci. Rep. 2016, 6, 37589. [CrossRef]

18. Chambers, E.S.; Viardot, A.; Psichas, A.; Morrison, D.J.; Murphy, K.G.; Zac-Varghese, S.E.; MacDougall, K.; Preston, T.; Tedford, C.; Finlayson, G.S.; et al. Effects of targeted delivery of propionate to the human colon on appetite regulation, body weight maintenance and adiposity in overweight adults. Gut 2015, 64, 1744-1754. [CrossRef]

19. Den Besten, G.; Lange, K.; Havinga, R.; van Dijk, T.H.; Gerding, A.; van Eunen, K.; Muller, M.; Groen, A.K.; Hooiveld, G.J.; Bakker, B.M.; et al. Gut-derived short-chain fatty acids are vividly assimilated into host carbohydrates and lipids. Am. J. Physiol. Gastrointest. Liver Physiol. 2013, 305, G900-G910. [CrossRef]

20. Beauvieux, M.C.; Roumes, H.; Robert, N.; Gin, H.; Rigalleau, V.; Gallis, J.L. Butyrate ingestion improves hepatic glycogen storage in the re-fed rat. BMC Physiol. 2008, 8, 19. [CrossRef]

21. Gao, Z.; Yin, J.; Zhang, J.; Ward, R.E.; Martin, R.J.; Lefevre, M.; Cefalu, W.T.; Ye, J. Butyrate improves insulin sensitivity and increases energy expenditure in mice. Diabetes 2009, 58, 1509-1517. [CrossRef]

22. Murakami, Y.; Ojima-Kato, T.; Saburi, W.; Mori, H.; Matsui, H.; Tanabe, S.; Suzuki, T. Supplemental epilactose prevents metabolic disorders through uncoupling protein-1 induction in the skeletal muscle of mice fed high-fat diets. Br. J. Nutr. 2015, 114, 1774-1783. [CrossRef] [PubMed]

23. Canfora, E.E.; Blaak, E.E. The role of polydextrose in body weight control and glucose regulation. Curr. Opin. Clin. Nutr. Metab. Care 2015, 18, 395-400. [CrossRef]

24. Den Besten, G.; Bleeker, A.; Gerding, A.; van Eunen, K.; Havinga, R.; van Dijk, T.H.; Oosterveer, M.H.; Jonker, J.W.; Groen, A.K.; Reijngoud, D.J.; et al. Short-Chain Fatty Acids Protect Against High-Fat Diet-Induced Obesity via a PPARgamma-Dependent Switch From Lipogenesis to Fat Oxidation. Diabetes 2015, 64, 2398-2408. [CrossRef] 
25. Frampton, J.; Murphy, K.G.; Frost, G.; Chambers, E.S. Short-chain fatty acids as potential regulators of skeletal muscle metabolism and function. Nat. Metab. 2020, 2, 840-848. [CrossRef]

26. Ndou, S.P.; Kiarie, E.; Walsh, M.C.; Ames, N.; de Lange, C.F.M.; Nyachoti, C.M. Interactive effects of dietary fibre and lipid types modulate gastrointestinal flows and apparent digestibility of fatty acids in growing pigs. Br. J. Nutr. 2019, 121, 469-480. [CrossRef] [PubMed]

27. Wealleans, A.L.; Bierinckx, K.; di Benedetto, M. Fats and oils in pig nutrition: Factors affecting digestion and utilization. Anim. Feed Sci. Tech. 2021, 277, 114950. [CrossRef]

28. Polakof, S.; Remond, D.; Bernalier-Donadille, A.; Rambeau, M.; Pujos-Guillot, E.; Comte, B.; Dardevet, D.; Savary-Auzeloux, I. Metabolic adaptations to HFHS overfeeding: How whole body and tissues postprandial metabolic flexibility adapt in Yucatan mini-pigs. Eur. J. Nutr. 2018, 57, 119-135. [CrossRef]

29. Savary-Auzeloux, I.; Mohamed, A.B.; Cohade, B.; Dardevet, D.; David, J.; Hafnaoui, N.; Migne, C.; Pujos-Guillot, E.; Remond, D.; Polakof, S. Profound Changes in Net Energy and Nitrogen Metabolites Fluxes within the Splanchnic Area during Overfeeding of Yucatan Mini Pigs That Remain Euglycemic. Nutrients 2019, 11, 434. [CrossRef]

30. Poupin, N.; Tremblay-Franco, M.; Amiel, A.; Canlet, C.; Rémond, D.; Debrauwer, L.; Dardevet, D.; Thiele, I.; Aurich, M.K.; Jourdan, F; et al. Arterio-venous metabolomics exploration reveals major changes across liver and intestine in the obese Yucatan minipig. Sci. Rep. 2019, 9, 12527. [CrossRef]

31. Arufe, S.; Chiron, H.; Dore, J.; Savary-Auzeloux, I.; Saulnier, L.; Della Valle, G. Processing \& rheological properties of wheat flour dough and bread containing high levels of soluble dietary fibres blends. Food Res. Int. (Ott. Ont.) 2017, 97, 123-132. [CrossRef]

32. Katz, M.L.; Bergman, E.N. Simultaneous measurements of hepatic and portal venous blood flow in the sheep and dog. Am. J. Physiol. 1969, 216, 946-952. [CrossRef] [PubMed]

33. Barbe, F.; Menard, O.; Le Gouar, Y.; Buffiere, C.; Famelart, M.H.; Laroche, B.; Le Feunteun, S.; Dupont, D.; Remond, D. The heat treatment and the gelation are strong determinants of the kinetics of milk proteins digestion and of the peripheral availability of amino acids. Food Chem. 2013, 136, 1203-1212. [CrossRef] [PubMed]

34. Huntington, G.B. Portal blood flow and net absorption of ammonia-nitrogen, urea-nitrogen, and glucose in nonlactating Holstein cows. J. Dairy Sci. 1982, 65, 1155-1162. [CrossRef]

35. Rodriguez-Lopez, J.M.; Cantalapiedra-Hijar, G.; Durand, D.; Isserty-Thomas, A.; Ortigues-Marty, I. Influence of the paraaminohippuric acid analysis method on the net hepatic flux of nutrients in lactating cows. J. Anim. Sci. 2014, 92, 1074-1082. [CrossRef]

36. Pouteau, E.; Meirim, I.; Metairon, S.; Fay, L.B. Acetate, propionate and butyrate in plasma: Determination of the concentration and isotopic enrichment by gas chromatography/mass spectrometry with positive chemical ionization. J. Mass Spectrom. JMS 2001, 36, 798-805. [CrossRef]

37. Gao, X.; Pujos-Guillot, E.; Sebedio, J.L. Development of a quantitative metabolomic approach to study clinical human fecal water metabolome based on trimethylsilylation derivatization and GC/MS analysis. Anal. Chem. 2010, 82, 6447-6456. [CrossRef]

38. Watt, M.J.; Hoy, A.J. Lipid metabolism in skeletal muscle: Generation of adaptive and maladaptive intracellular signals for cellular function. Am. J. Physiol. Endocrinol. Metab. 2012, 302, E1315-E1328. [CrossRef] [PubMed]

39. Gueugneau, M.; Coudy-Gandilhon, C.; Theron, L.; Meunier, B.; Barboiron, C.; Combaret, L.; Taillandier, D.; Polge, C.; Attaix, D.; Picard, B.; et al. Skeletal muscle lipid content and oxidative activity in relation to muscle fiber type in aging and metabolic syndrome. J. Gerontol. Ser. A Biol. Sci. Med. Sci. 2015, 70, 566-576. [CrossRef]

40. Malenfant, P.; Joanisse, D.R.; Theriault, R.; Goodpaster, B.H.; Kelley, D.E.; Simoneau, J.A. Fat content in individual muscle fibers of lean and obese subjects. Int. J. Obes. Relat. Metab. Disord. J. Int. Assoc. Study Obes. 2001, 25, 1316-1321. [CrossRef]

41. Gavin, T.P.; Stallings, H.W.; Zwetsloot, K.A.; Westerkamp, L.M.; Ryan, N.A.; Moore, R.A.; Pofahl, W.E.; Hickner, R.C. Lower capillary density but no difference in VEGF expression in obese vs. lean young skeletal muscle in humans. J. Appl. Physiol. 2005, 98, 315-321. [CrossRef] [PubMed]

42. Clark, B.A.; Alloosh, M.; Wenzel, J.W.; Sturek, M.; Kostrominova, T.Y. Effect of diet-induced obesity and metabolic syndrome on skeletal muscles of Ossabaw miniature swine. Am. J. Physiol. Endocrinol. Metab. 2011, 300, E848-E857. [CrossRef]

43. Guillerm-Regost, C.; Louveau, I.; Sebert, S.P.; Damon, M.; Champ, M.M.; Gondret, F. Cellular and biochemical features of skeletal muscle in obese Yucatan minipigs. Obesity 2006, 14, 1700-1707. [CrossRef]

44. Tanner, C.J.; Barakat, H.A.; Dohm, G.L.; Pories, W.J.; MacDonald, K.G.; Cunningham, P.R.; Swanson, M.S.; Houmard, J.A. Muscle fiber type is associated with obesity and weight loss. Am. J. Physiol. Endocrinol. Metabol. 2002, 282, E1191-E1196. [CrossRef]

45. Togawa, N.; Takahashi, R.; Hirai, S.; Fukushima, T.; Egashira, Y. Gene expression analysis of the liver and skeletal muscle of psyllium-treated mice. Br. J. Nutr. 2013, 109, 383-393. [CrossRef]

46. Kelley, D.E.; He, J.; Menshikova, E.V.; Ritov, V.B. Dysfunction of mitochondria in human skeletal muscle in type 2 diabetes. Diabetes 2002, 51, 2944-2950. [CrossRef]

47. Szendroedi, J.; Phielix, E.; Roden, M. The role of mitochondria in insulin resistance and type 2 diabetes mellitus. Nat. Rev. Endocrinol. 2011, 8, 92-103. [CrossRef] [PubMed]

48. Rieusset, J. Contribution of mitochondria and endoplasmic reticulum dysfunction in insulin resistance: Distinct or interrelated roles? Diabetes Metab. 2015, 41, 358-368. [CrossRef] [PubMed] 
49. Whytock, K.L.; Shepherd, S.O.; Wagenmakers, A.J.M.; Strauss, J.A. Hormone-sensitive lipase preferentially redistributes to lipid droplets associated with perilipin-5 in human skeletal muscle during moderate-intensity exercise. J. Physiol. 2018, 596, 2077-2090. [CrossRef]

50. Devarshi, P.P.; McNabney, S.M.; Henagan, T.M. Skeletal Muscle Nucleo-Mitochondrial Crosstalk in Obesity and Type 2 Diabetes. Int. J. Mol. Sci. 2017, 18, 831. [CrossRef]

51. Mootha, V.K.; Lindgren, C.M.; Eriksson, K.F.; Subramanian, A.; Sihag, S.; Lehar, J.; Puigserver, P.; Carlsson, E.; Ridderstrale, M.; Laurila, E.; et al. PGC-1alpha-responsive genes involved in oxidative phosphorylation are coordinately downregulated in human diabetes. Nat. Genet. 2003, 34, 267-273. [CrossRef] [PubMed]

52. Handschin, C.; Spiegelman, B.M. The role of exercise and PGC1alpha in inflammation and chronic disease. Nature 2008, 454, 463-469. [CrossRef] [PubMed]

53. Hong, J.; Jia, Y.; Pan, S.; Jia, L.; Li, H.; Han, Z.; Cai, D.; Zhao, R. Butyrate alleviates high fat diet-induced obesity through activation of adiponectin-mediated pathway and stimulation of mitochondrial function in the skeletal muscle of mice. Oncotarget 2016, 7, 56071-56082. [CrossRef]

54. Brockman, D.A.; Chen, X.; Gallaher, D.D. High-viscosity dietary fibers reduce adiposity and decrease hepatic steatosis in rats fed a high-fat diet. J. Nutr. 2014, 144, 1415-1422. [CrossRef] [PubMed]

55. Ma, Q. Role of nrf2 in oxidative stress and toxicity. Ann. Rev. Pharmacol. Toxicol. 2013, 53, 401-426. [CrossRef]

56. Finck, B.N.; Bernal-Mizrachi, C.; Han, D.H.; Coleman, T.; Sambandam, N.; LaRiviere, L.L.; Holloszy, J.O.; Semenkovich, C.F.; Kelly, D.P. A potential link between muscle peroxisome proliferator- activated receptor-alpha signaling and obesity-related diabetes. Cell Metab. 2005, 1, 133-144. [CrossRef]

57. Van Wessel, T.; de Haan, A.; van der Laarse, W.J.; Jaspers, R.T. The muscle fiber type-fiber size paradox: Hypertrophy or oxidative metabolism? Eur. J. Appl. Physiol. 2010, 110, 665-694. [CrossRef]

58. Nickerson, J.G.; Alkhateeb, H.; Benton, C.R.; Lally, J.; Nickerson, J.; Han, X.X.; Wilson, M.H.; Jain, S.S.; Snook, L.A.; Glatz, J.F.; et al. Greater transport efficiencies of the membrane fatty acid transporters FAT/CD36 and FATP4 compared with FABPpm and FATP1 and differential effects on fatty acid esterification and oxidation in rat skeletal muscle. J. Biol. Chem. 2009, 284, 16522-16530. [CrossRef]

59. Jain, S.S.; Luiken, J.J.; Snook, L.A.; Han, X.X.; Holloway, G.P.; Glatz, J.F.; Bonen, A. Fatty acid transport and transporters in muscle are critically regulated by Akt2. FEBS Lett. 2015, 589, 2769-2775. [CrossRef]

60. Weng, H.; Endo, K.; Li, J.; Kito, N.; Iwai, N. Induction of peroxisomes by butyrate-producing probiotics. PLoS ONE 2015, 10, e0117851. [CrossRef]

61. Aryal, B.; Singh, A.K.; Zhang, X.; Varela, L.; Rotllan, N.; Goedeke, L.; Chaube, B.; Camporez, J.P.; Vatner, D.F.; Horvath, T.L.; et al. Absence of ANGPTL4 in adipose tissue improves glucose tolerance and attenuates atherogenesis. JCI Insight 2018, 3 , e97918. [CrossRef] [PubMed]

62. Yamada, T.; Ozaki, N.; Kato, Y.; Miura, Y.; Oiso, Y. Insulin downregulates angiopoietin-like protein 4 mRNA in 3T3-L1 adipocytes. Biochem. Biophys. Res. Commun. 2006, 347, 1138-1144. [CrossRef]

63. Fitch, M.D.; Fleming, S.E. Metabolism of short-chain fatty acids by rat colonic mucosa in vivo. Am. J. Physiol. 1999, 277, G31-G40. [CrossRef] [PubMed]

64. Adeva-Andany, M.; Lopez-Ojen, M.; Funcasta-Calderon, R.; Ameneiros-Rodriguez, E.; Donapetry-Garcia, C.; Vila-Altesor, M.; Rodriguez-Seijas, J. Comprehensive review on lactate metabolism in human health. Mitochondrion 2014, 17, 76-100. [CrossRef]

65. Pozefsky, T.; Tancredi, R.G. Effects of intrabrachial arterial infusion of pyruvate on forearm tissue metabolism. Interrelationships between pyruvate, lactate, and alanine. J. Clin. Investig. 1972, 51, 2359-2369. [CrossRef]

66. Small, L.; Brandon, A.E.; Quek, L.E.; Krycer, J.R.; James, D.E.; Turner, N.; Cooney, G.J. Acute activation of pyruvate dehydrogenase increases glucose oxidation in muscle without changing glucose uptake. Am. J. Physiol. Endocrinol. Metab. 2018, 315, E258-E266. [CrossRef] [PubMed]

67. Sugden, M.C.; Lall, H.S.; Harris, R.A.; Holness, M.J. Selective modification of the pyruvate dehydrogenase kinase isoform profile in skeletal muscle in hyperthyroidism: Implications for the regulatory impact of glucose on fatty acid oxidation. J. Endocrinol. 2000, 167, 339-345. [CrossRef] [PubMed]

68. Den Besten, G.; Gerding, A.; van Dijk, T.H.; Ciapaite, J.; Bleeker, A.; van Eunen, K.; Havinga, R.; Groen, A.K.; Reijngoud, D.J.; Bakker, B.M. Protection against the Metabolic Syndrome by Guar Gum-Derived Short-Chain Fatty Acids Depends on Peroxisome Proliferator-Activated Receptor gamma and Glucagon-Like Peptide-1. PLoS ONE 2015, 10, e0136364. [CrossRef]

69. De Vadder, F.; Kovatcheva-Datchary, P.; Goncalves, D.; Vinera, J.; Zitoun, C.; Duchampt, A.; Backhed, F.; Mithieux, G. Microbiotagenerated metabolites promote metabolic benefits via gut-brain neural circuits. Cell 2014, 156, 84-96. [CrossRef]

70. Bach Knudsen, K.E.; Jorgensen, H.; Canibe, N. Quantification of the absorption of nutrients derived from carbohydrate assimilation: Model experiment with catheterised pigs fed on wheat- or oat-based rolls. Br. J. Nutr. 2000, 84, 449-458. [CrossRef]

71. Theil, P.K.; Jorgensen, H.; Serena, A.; Hendrickson, J.; Bach Knudsen, K.E. Products deriving from microbial fermentation are linked to insulinaemic response in pigs fed breads prepared from whole-wheat grain and wheat and rye ingredients. Br. J. Nutr. 2011, 105, 373-383. [CrossRef] [PubMed]

72. Mischke, M.; Plosch, T. The Gut Microbiota and their Metabolites: Potential Implications for the Host Epigenome. Adv. Exp. Med. Biol. 2016, 902, 33-44. [CrossRef] 
73. Martin, L.; Dumon, H.; Lecannu, G.; Champ, M. Potato and high-amylose maize starches are not equivalent producers of butyrate for the colonic mucosa. Br. J. Nutr. 2000, 84, 689-696. [CrossRef]

74. Amato, A.; Baldassano, S.; Mule, F. GLP2: An underestimated signal for improving glycaemic control and insulin sensitivity. J. Endocrinol. 2016, 229, R57-R66. [CrossRef]

75. Thulesen, J.; Hartmann, B.; Nielsen, C.; Holst, J.J.; Poulsen, S.S. Diabetic intestinal growth adaptation and glucagon-like peptide 2 in the rat: Effects of dietary fibre. Gut 1999, 45, 672-678. [CrossRef] [PubMed]

76. Zander, M.; Madsbad, S.; Madsen, J.L.; Holst, J.J. Effect of 6-week course of glucagon-like peptide 1 on glycaemic control, insulin sensitivity, and beta-cell function in type 2 diabetes: A parallel-group study. Lancet 2002, 359, 824-830. [CrossRef]

77. De Vadder, F.; Kovatcheva-Datchary, P.; Zitoun, C.; Duchampt, A.; Backhed, F.; Mithieux, G. Microbiota-Produced Succinate Improves Glucose Homeostasis via Intestinal Gluconeogenesis. Cell Metab. 2016, 24, 151-157. [CrossRef] [PubMed]

78. Weitkunat, K.; Schumann, S.; Nickel, D.; Hornemann, S.; Petzke, K.J.; Schulze, M.B.; Pfeiffer, A.F.; Klaus, S. Odd-chain fatty acids as a biomarker for dietary fiber intake: A novel pathway for endogenous production from propionate. Am. J. Clin. Nutr. 2017, 105, 1544-1551. [CrossRef]

79. Krautkramer, K.A.; Fan, J.; Bäckhed, F. Gut microbial metabolites as multi-kingdom intermediates. Nat. Rev. Microbiol. 2020, 19, 77-94. [CrossRef] 